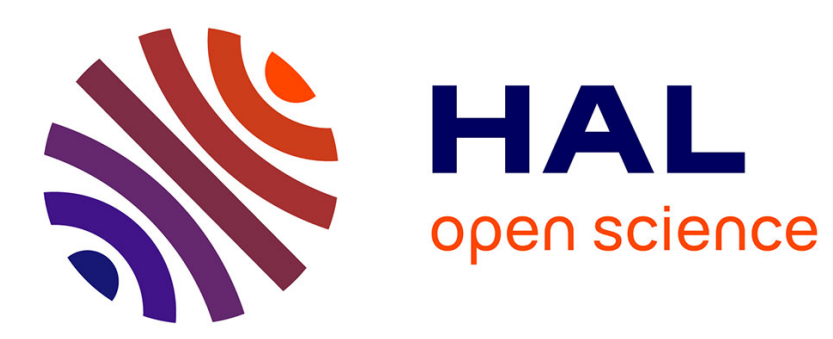

\title{
The Peculiar Features of Non-Photochemical Fluorescence Quenching in Diatoms and Brown Algae \\ Johann Lavaud, Reimund Goss
}

\section{To cite this version:}

Johann Lavaud, Reimund Goss. The Peculiar Features of Non-Photochemical Fluorescence Quenching in Diatoms and Brown Algae. Non-Photochemical Quenching and Energy Dissipation in Plants, Algae and Cyanobacteria, , pp.421 - 443, 2014, 10.1007/978-94-017-9032-1_20 . hal-01096599

\section{HAL Id: hal-01096599 \\ https://hal.science/hal-01096599}

Submitted on 17 Dec 2014

HAL is a multi-disciplinary open access archive for the deposit and dissemination of scientific research documents, whether they are published or not. The documents may come from teaching and research institutions in France or abroad, or from public or private research centers.
L'archive ouverte pluridisciplinaire HAL, est destinée au dépôt et à la diffusion de documents scientifiques de niveau recherche, publiés ou non, émanant des établissements d'enseignement et de recherche français ou étrangers, des laboratoires publics ou privés. 


\section{Chapter 20}

The Peculiar Features of Non-Photochemical Fluorescence Quenching in Diatoms and Brown Algae

Johann Lavaud* ${ }^{1}$ and Reimund Goss ${ }^{2}$

${ }^{1}$ UMR 7266 'LIENSs', CNRS/University of La Rochelle, Institute for Coastal Research and Environment (ILE), 2 rue Olympe de Gouges, 17000 La Rochelle cedex, France;

${ }^{2}$ Institute of Biology, Department of Plant Physiology, University of Leipzig, Johannisallee 21-23, 04103 Leipzig, Germany

*Author for correspondence: Fax: +33-5-46-45-82-64; e-mail: johann.lavaud@univ-lr.fr

Running title: NPQ in Diatoms and Brown Algae 
Summary

I. Introduction

II. Xanthophyll Cycle-Dependent NPQ

A. Xanthophyll Cycles of Diatoms and Brown Algae

1. Diatoms

2. Brown algae

B. Mechanism of Xanthophyll-Dependent NPQ

1. Diatoms

2. Brown algae

C. Regulation of Xanthophyll Cycle-Dependent NPQ

III. Importance of the Xanthophyll Cycle and NPQ in the Field
A. Diatoms of the Phytoplankton
B. Diatoms of the Microphytobenthos
C. Brown Algae

IV. Conclusion

Acknowledgments

References 


\section{Summary}

Diatoms and brown algae are major contributors to marine primary production. They are biologically diverse, with thousands of different species, and are extremely successful, occupying almost every marine ecosystem ranging from the coastal-estuarine to deep-sea regions. Their ecological success is based in part on their ability to rapidly regulate photosynthesis in response to pronounced fluctuations in their natural light environment. Regulation of light harvesting, and the use of excitation energy, is largely based on effective dissipation of excessive energy as heat. Thermal dissipation of excitation energy is assessed as non-photochemical quenching of chlorophyll $a$ fluorescence (NPQ). NPQ depends strongly on the conversion of xanthophylls: diadinoxanthin (Dd) to diatoxanthin (Dt) in the Dd-Dt cycle of diatoms and violaxanthin $(\mathrm{V})$ to zeaxanthin $(\mathrm{Z})$, via the intermediate antheraxanthin (A), in the VAZ cycle present in brown algae. Xanthophyll cycle (XC)-dependent thermal energy dissipation underlying NPQ represents one of the most important photoprotection mechanisms of diatoms and brown algae. In the present chapter, we review the biochemistry of XC enzymes with a special focus on co-substrate requirements and regulation of enzyme activity. In addition, we present a new model for the structural basis of XC-dependent NPQ in diatoms based on the latest experimental findings. In the last section, we highlight the importance of XC-dependent photoprotection for the ecological success of diatoms and brown algae in their natural environments.

\section{Abbreviations}

A antheraxanthin

Asc Ascorbate

Chl $a$ chlorophyll $a$

Chl $a_{710-712}$ chlorophyll $a$ fluorescence emission band between 710 and $712 \mathrm{~nm}$ 
Dd diadinoxanthin

DDE diadinoxanthin de-epoxidase

DES diadinoxanthin de-epoxidation state

DEP diadinoxanthin epoxidase

Dt diatoxanthin

DTT dithiothreitol

FCP fucoxanthin chlorophyll protein

FCPa, FCPb, FCPo, Fcp6 fucoxanthin chlorophyll protein complex 'a', fucoxanthin chlorophyll protein complex 'b', fucoxanthin chlorophyll protein complex 'o', fucoxanthin chlorophyll protein '6' (= Lhcx1)

$\mathrm{H}^{+} \quad$ protons

LHC light-harvesting complex

Lhcf, Lhcx light-harvesting complex protein binding fucoxanthin, light-harvesting complex protein ' $\mathrm{x}$ '

LHCSR stress-related light-harvesting complex protein (= LI818)

LHC7, LHC8 light-harvesting complex protein '7', light-harvesting complex protein '8'

LI818 light-induced light-harvesting complex protein ' 818 '

MGDG monogalactosyldiacylgycerol

MPB microphytobenthic

Ndh $\quad \mathrm{NAD}(\mathrm{P}) \mathrm{H}$ dehydrogenase

NPQ non-photochemical quenching of chlorophyll fluorescence

OEC oxygen evolving complex

PQ plastoquinone

PS II photosystem II

PS II RC photosystem II reaction center 
qE 'energy- or pH-dependent' quenching

qI 'photoinhibitory' quenching

qT 'state-transition’ quenching

Q1 and Q2 quenching sites 1 and 2

SQDG sulfoquinovosyldiacylglycerol

VDE violaxanthin de-epoxidase

V violaxanthin

XC xanthophyll cycle

ZEP zeaxanthin epoxidase

Z zeaxanthin

$\Delta \mathrm{pH} \quad$ transthylakoid proton gradient

$\Delta 522 \mathrm{~nm} \quad$ absorption change at $522 \mathrm{~nm}$.

$\mathrm{H}_{\text {II }} \quad$ MGDG inverted hexagonal phase 


\section{Introduction}

In marine ecosystems, the main in situ abiotic driving forces for autotrophic growth are temperature, nutrients and light, the latter showing the highest variations in amplitude and frequency (MacIntyre et al. 2000; Kirk 2011). Consequently, the response of algae to their natural light environment is influenced by at least one irradiance-dependent process ( $\mathrm{Li}$ et al. 2009). Because rapid light fluctuations are unpredictable, this process must be fast and flexible. The xanthophyll (XC)-dependent non-photochemical quenching of chlorophyll (Chl) $a$ fluorescence (NPQ) turns out to provide such features. Photoprotective thermal energy dissipation that is reflected in NPQ is one of the main physiological processes used by algae to respond to the fluctuations of their natural light environment (Lavaud 2007; Brunet and Lavaud 2010; Goss and Jakob 2010; Depauw et al. 2012; Niyogi and Truong 2013). Diatoms and brown macroalgae can exert a strong NPQ (Lavaud et al. 2002a; Ruban et al. 2004; Lavaud 2007; Garcia-Mendoza and Colombo-Pallotta 2007).

Diatoms, as well as macrophytic brown algae (Phaeophyceae), belong to the stramenopiles that are classified as Chromista (Kooistra et al. 2007). The chloroplasts of the Chromista are most likely the result of different endosymbiotic events, including a significant gene transfer from red algal and from prasinophyte cells (Frommolt et al. 2008; Moustafa et al. 2009). Among the genes that were retained are the ones encoding for the XC enzymes violaxanthin (V) de-epoxidase (VDE) and zeaxanthin (Z) epoxidase (ZEP). It was suggested that the latter genes were retained because, through the control of thermal energy dissipation underlying NPQ, the XC provides an efficient photoprotection mechanism, thereby improving photosynthetic performance (Frommolt et al. 2008). The plastids of the stramenopiles are further characterized by the existence of four envelope membranes and by a different pigment assemblage (Wilhelm et al. 2006; Lavaud 2007; Lepetit et al. 2012). The thylakoid 
membranes are arranged in regular stacks of three with no grana systems as in vascular plants (Pyszniak and Gibbs 1992).

Diatoms show a fascinating biodiversity with up to 100,000 different species divided into three clades and two morphological groups: the pennates and the centrics (longitudinal versus radial symmetry, respectively) (Kooistra et al. 2007). Planktonic diatoms evolved from benthic forms (Kooistra et al. 2007). Diatoms are almost equally distributed in marine and limnic habitats (Falkowski et al. 2004) and they are major contributors to marine primary production (Armbrust et al. 2009). The light-harvesting system of diatoms consists of the fucoxanthin-chlorophyll protein (FCP) complexes that form oligomers whose organization is groups-/species-dependent (see Büchel, Chap. 11). In addition to the peripheral, main lightharvesting complex (LHC), which serves as antenna for both photosystem I (PS I) and II (PS II), diatoms contain a specific PS I FCP complex (Veith et al. 2009; Lepetit et al. 2010). FCP complexes are apoproteins of up to 18-19 kDa (Wilhelm et al. 2006; Lavaud 2007; Lepetit et al. 2012). The pigments of the XC cycle involving diadinoxanthin (=Dd) and diatoxanthin (=Dt) are bound to FCPs or located in a monogalactosyldiacylgycerol (MGDG) shield around the peripheral FCP complexes (Lepetit et al. 2010). These complexes are the site, where the majority of energy dissipation that results in NPQ takes place (see Büchel, Chap. 11).

Macrophytic brown algae are important coastal primary producers (Enriquez and Borowitzka 2010). There are about 2000 known species (de Reviers and Rousseau 1999) whose phylogeny is still under debate (Philips et al. 2008). Their morphology is extremely diverse, with forms ranging from microscopic filaments to the well-known macrophytes like the Fucales and the Laminariales. Most of them are sessile organisms with few pelagic (open water) species. The LHC system of brown algae is also composed of FCP complexes (Dittami et al. 2010). The latter are isolated as trimeric units of 20-kDa apoproteins (De Martino et al. 1997; Fujii et al. 2012) that can possibly form higher dodecameric structures (Katoh et al. 
1989; Passaquet et al. 1991). These complexes exhibit pigmentation similar to that of the corresponding complexes in diatoms, with the exception of the $\mathrm{XC}$ pigments that are the same as in green algae and vascular plants, i.e. V, antheraxanthin (A), and Z (Passaquet et al. 1991).

The variability of the XC-NPQ responses among lineages/genera/species has been a matter of growing debate. It was suggested that XC-NPQ diversity, and to a larger extent the diversity of photoadaptative strategy and capacity, would contribute to promoting competitive exclusion and spatial co-existence and/or temporal succession of algae in both pelagic and benthic (region along the bottom) systems (see Brunet and Lavaud 2010; Goss and Jakob 2010). The high efficiency of photoprotective XC-dependent energy dissipation underlying NPQ could also explain the amazing capacity of diatoms and brown algae to exploit differences in underwater light climate and to occupy a wide range of ecological niches.

\section{Xanthophyll Cycle-Dependent NPQ}

\section{A. Xanthophyll Cycles of Diatoms and Brown Algae}

\section{Diatoms}

Diatoms possess both the VAZ and the Dd-Dt cycle (Lohr 2011). While the Dd-Dt cycle is the main $\mathrm{XC}$ and is essential for NPQ, the VAZ-cycle pigment V serves as precursor pigment in the biosynthesis of Dd and the main light-harvesting xanthophyll fucoxanthin (Lohr 2011; Dambek et al. 2012). In line with their function as xanthophyll synthesis intermediates, the VAZ-cycle pigments are only present in significant amounts after exposure to prolonged excess light, which triggers profound de-novo carotenoid synthesis (Lohr and Wilhelm 1999).

The Dd-Dt cycle (Fig. 1) consists of a de-epoxidation step from Dd, with one epoxy group, to the epoxy-free Dt (Lohr 2011). The back epoxidation reaction re-introduces the epoxy group into the Dt molecule. De-epoxidation from Dd to Dt takes place under excess light intensities but may also be triggered during long periods of darkness (Jakob et al. 1999, 
2001; Cruz et al. 2011) (see Section II.C). Epoxidation is usually observed during periods of low light or darkness that follow excess light exposure (Goss et al. 2006a).

\section{Typesetter to place Figure 1 here}

De-epoxidation is catalyzed by the enzyme Dd de-epoxidase (DDE) while Dt epoxidase (DEP) triggers the epoxidation. Important differences exist between the latter two enzymes and the respective enzymes of the VAZ cycle of vascular plants, VDE and ZEP. DDE exhibits a different pH-dependence (Jakob et al. 2001); while VDE activity occurs at pH values of 6.5 or lower, DDE activity can already be observed at neutral $\mathrm{pH}$ values. The $\mathrm{pH}$ optimum of DDE is also shifted to higher $\mathrm{pH}$ values (5.5) in isolated thylakoids of diatoms as compared to VDE (Jakob et al. 2001; Grouneva et al. 2006). These differences imply that, in diatoms, Dd de-epoxidation can be triggered by a lower light-driven proton gradient across the thylakoid membrane $(\Delta \mathrm{pH})$ (see Section II.C). It is not clear if DDE activation at less acidic $\mathrm{pH}$ values results in a conformational change of the enzyme as has been proposed for VDE of vascular plants. Inactive VDE is monomeric, and forms a dimer after exposure to low/acid pH values (Arnoux et al. 2009; Saga et al. 2010). It has been proposed that the dimeric form of VDE is able to simultaneously de-epoxidize both epoxy groups of V (Arnoux et al. 2009). Such a direct de-epoxidation of $\mathrm{V}$ to $\mathrm{Z}$ is, however, in contrast to the various studies that describe $\mathrm{V}$ de-epoxidation under natural conditions in intact plant leaves. These studies have shown that a significant accumulation of A can occur during the morning with increasing light intensities and during the afternoon when the irradiance decreases (Adams and Demmig-Adams 1992).

Since Dd de-epoxidation only comprises one de-epoxidation step, the greatest advantage of dimeric VDE, i.e. simultaneous de-epoxidation of both epoxy-groups of V, does not apply to the Dd-Dt cycle. Additionally, DDE exhibits a significantly lower $\mathrm{K}_{\mathrm{M}}$ value (than VDE) for the co-substrate of de-epoxidation, ascorbate (Grouneva et al. 2006). The $\mathrm{K}_{\mathrm{M}}$ value 
for isolated DDE of Cyclotella meneghiniana is $0.7 \mathrm{mM}$ versus $2.3 \mathrm{mM}$ for VDE of spinach. DDE is also able to maintain efficient de-epoxidation in the presence of very low concentrations of ascorbate, although this leads to a shift of the $\mathrm{pH}$-optimum towards lower pH values (Grouneva et al. 2006). The optimized co-substrate usage of DDE indicates that the diatom cell is not providing a high concentration of ascorbate for Dd de-epoxidation.

A further, albeit more indirect, optimization is seen in the lipid requirement of the deepoxidation. Efficient Dd de-epoxidation depends on presence of the main thylakoid lipid MGDG (Goss et al. 2005, 2007). MGDG serves to solubilize the hydrophobic pigment Dd, making it accessible for DDE. For the complete solubilization of a certain amount of Dd, a lower concentration of MGDG is sufficient than for the same number of V molecules (Goss et al. 2005, 2007). This increased solubilization efficiency of Dd is in line with the often large $\mathrm{XC}$ pigment pool of diatoms with values of up to $800 \mathrm{mM} \mathrm{Dd+Dt} \mathrm{per} \mathrm{M} \mathrm{Chl} a$ (Lavaud et al. 2003; Lepetit et al. 2010). A higher number of Dd molecules can presumably be incorporated into the MGDG phase, resulting in increased de-epoxidation (Lavaud et al. 2003). A high concentration of Dt in the thylakoid lipid phase is in line with increased photoprotection by Dt (Lepetit et al. 2010). Additionally, MGDG forms what are termed inverted hexagonal $\left(\mathrm{H}_{\mathrm{II}}\right)$ phases essential for efficient de-epoxidation (Latowski et al. 2002; Goss et al. 2005, 2007). $\mathrm{H}_{\text {II }}$ phases are likely associated with the FCP complexes and represent the docking sites for DDE once the enzyme has been activated by $\Delta \mathrm{pH}$ (Lepetit et al. 2010, 2012), i.e. the MGDG shield around the LHC targets DDE to the site where the majority of Dd is located.

The DEP also shows significant differences compared to ZEP, especially with regard to the epoxidation kinetics that can be almost 20 fold higher (Goss et al. 2006a). Consequently, while $\mathrm{Z}$ epoxidation in vascular plants and green algae is slow compared to $\mathrm{V}$ de-epoxidation (Goss et al. 2006b; Schaller et al. 2012), Dt epoxidation is fast and can almost equal the Dd de-epoxidation kinetics. The extremely fast Dt epoxidation must be viewed in 
conjunction with the differences in the mechanism of Dt- and Z-dependent NPQ (Goss et al. 2006a; Goss and Jakob 2010) (see Section II.B.1). While Z normally quenches Chl $a$ fluorescence non-photochemically in the presence of $\Delta \mathrm{pH}$, Dt maintains a stable NPQ after $\Delta \mathrm{pH}$ relaxation dissipation. This stable quenching is comparable to a certain type of stable, $\Delta \mathrm{pH}$-independent $\mathrm{Z}$ quenching seen in evergreen plants during the winter or subjected to water stress, or low light-grown plants subjected to excess light (Demmig-Adams and Adams 2006; Demmig-Adams et al. 2006; see Adams et al., Chap. 23, and Demmig-Adams et al., Chap. 24). Due to the stable Dt quenching, a complete disengagement of Dt from thermal energy dissipation and relaxation of NPQ is presumably possible only by efficient removal of Dt from its FCP-binding sites. However, the possibility of an extremely fast Dt epoxidation poses a problem for the Dd-Dt cycle when, during excess light illumination, a fast net accumulation of Dt is needed to trigger thermal energy dissipation resulting in NPQ (Lavaud et al. 2002b; Goss et al. 2006a; Lepetit et al. 2013) (see Section II.B.1). Without an efficient control of Dt epoxidation, excess light could not result in a fast and strong increase of Dt concentration. Therefore, it is of great importance that DEP be under the strict control of light-driven $\Delta \mathrm{pH}$, i.e. $\Delta \mathrm{pH}$ almost completely inhibits epoxidation of Dt (Mewes and Richter 2002; Goss et al. 2006a). The mechanism of this inactivation is, however, still unknown. Nevertheless, upon exposure to gradually increasing light intensities, a complete inactivation of the DEP can be circumvented (Dimier et al. 2009).

With respect to the localization of the $\mathrm{XC}$ enzymes, the pH-dependent activation of DDE and the NADPH requirement of DEP indicate that the enzymes are situated in the thylakoid lumen and on the stromal side of the thylakoid membrane, respectively, as it has been described for VDE and ZEP of vascular plants (Jahns et al. 2009; Latowski et al. 2011). The MGDG-requirement of Dd de-epoxidation indicates that DDE, like VDE (Schaller et al. 2010), binds to MGDG-enriched regions of the thylakoid membrane that are located in the 
vicinity of the FCP complexes (Lepetit et al. 2010). The binding of DDE to MGDG-enriched regions occurs after the DDE pH-activation. Whether DEP is a peripheral, loosely-bound membrane protein, as it has been recently suggested for ZEP (Schaller et al. 2012), remains to be assessed.

Genetic studies of the Dd-Dt cycle demonstrated that the genes encoding for DDE and DEP are closely related to the respective genes of the Prasinophytes (Frommolt et al. 2008). The comparable structure of the gene arrangement in diatoms and Prasinophytes, i.e. a cluster of the DDE-VDE gene with one of the multiple copies of the DEP-ZEP gene, further strengthens the notion that the Chromista have acquired the XC genes through an early endosymbiosis involving a primitive green alga, in addition to the later endosymbiosis events with red algae. A recent study reported the genetic manipulation of the DDE gene in Phaeodactylum tricornutum (Lavaud et al. 2012). By suppressing the transcript level of the DDE in vivo, it was possible to inhibit up to $50 \%$ of Dt synthesis and to strongly reduce the extent of NPQ, as well as to disturb the $\triangle \mathrm{pH}-\mathrm{Dt}-\mathrm{NPQ}$ relationship. Such approaches will help to decipher the mechanism underlying NPQ in diatoms in the future (see Section II.B.1).

\section{Brown Algae}

Unlike diatoms, brown algae only possess the VAZ cycle (Rodrigues et al. 2002; Gévaert et al. 2003; Garcia-Mendoza and Colombo-Pallotta 2007). The VAZ cycle (Fig. 1) consists of a two-step de-epoxidation from the di-epoxy xanthophyll $\mathrm{V}$ to $\mathrm{Z}$ via the intermediate $\mathrm{A}$ (Yamamoto et al. 1962; Hager 1967a,b,). This reaction sequence, taking place under excess light (as is the case for the VAZ cycle in plants and the Dd-Dt cyle in diatoms), is reversed in low light or in darkness. The enzymes catalyzing the forward and backward reaction are VDE and ZEP, respectively. Almost nothing is known about the biochemistry of these enzymes in brown algae. Since the overall characteristics of the XC, i.e. kinetic, rates of the first and 
second de-epoxidation and epoxidation steps, and ratio of the first to the second deepoxidation and epoxidation step, are generally comparable to vascular plants (Rodrigues et al. 2002), the properties of the VAZ-cycle enzymes in brown algae are most likely also comparable. However, V de-epoxidation may be slightly slower and $\mathrm{Z}$ epoxidation slightly faster in brown algae (Garcia-Mendoza et al. 2011). Brown algae thus exhibit slow Z epoxidation kinetics similar to those in vascular plants (Garcia-Mendoza and ColomboPallotta 2007). This means that, during a low-light or dark period following excess light illumination, a significant amount of $\mathrm{Z}$ remains bound to the FCP complexes. As described above for Dt in diatoms (see also Section II.B.1), $\mathrm{Z}$ in brown algae also seems to be able to contribute to a sustained NPQ even after $\Delta \mathrm{pH}$ relaxation (Garcia-Mendoza and ColomboPallotta 2007). Hence the structure/organization of the FCP complexes appears to be responsible for this stable Dt- or Z-dependent NPQ. In the LHC II complexes of vascular plants such a pronounced stable Z-dependent NPQ is normally not seen after $\Delta \mathrm{pH}$ relaxation (Goss et al. 2006a), but can be found in plants exposed to excess light for extended time periods with or without additional stresses (Demmig-Adams and Adams 2006; DemmigAdams et al. 2006; see also Adams et al., Chap. 23, and Demmig-Adams et al., Chap. 24). It remains an open question as to why brown algae are unable to epoxidize $\mathrm{Z}$ to $\mathrm{V}$ with comparably fast kinetics as observed for the conversion of Dt to Dd in diatoms. Based on the observation that the conversion rate of $\mathrm{A}$ to $\mathrm{V}$ in darkness decreases in $M$. pyrifera exposed to longer illumination periods (Ocampo-Alvarez et al. 2013), it has been proposed that the slow epoxidation reaction represents an adaptive strategy of brown algae to cope with light stress conditions. Maintaining A in the antenna system may allow for a faster response to saturating light by accelerating Z accumulation and NPQ induction (Garcia-Mendoza et al. 2011).

\section{B. Mechanism of Xanthophyll-Dependent NPQ}




\section{Diatoms}

In diatoms, NPQ is mainly composed of $\mathrm{qE}$, i.e. $\mathrm{pH}$ - or energy-dependent quenching (see Papageorgiou and Govindjee, Chap. 1, and Logan et al., Chap. 7 for a definition of the different quenching components). Indeed, qT, the NPQ component based on state-transitions, i.e. the reversible, wavelength-dependent translocation of part of the PS II antenna to PS I, seems to be absent in diatoms (Owens 1986). It is, however, still unclear if a light intensitydependent structural reorganization of PS II and PS I, which might lead to an increased spillover of excitation energy, takes place. The origin and mechanism of qI, the slowly reversible so-called "photoinhibitory" quenching, remain unclear, although it is likely that XC pigments are involved (Demmig-Adams and Adams 2006; see also Adams et al., Chap. 23, and Demmig-Adams et al., Chap. 24). Mechanistic models of xanthophyll-dependent NPQ in diatoms have been proposed before (Lavaud 2007; Goss and Jakob 2010; Lepetit et al. 2012) and significant recent advances have been made since (Miloslavina et al. 2009; Gundermann and Büchel 2012; Lavaud and Lepetit 2013). The following tentative NPQ model for pennate diatoms (Fig. 2, see Büchel, Chap. 11 for a model for centric diatoms) is based on the recent observation of two quenching sites (Q1 and Q2) in diatoms and vascular plants (Miloslavina et al. 2009; Jahns and Holzwarth 2012). The model includes differences observed between diatom cells exhibiting a low versus high NPQ amplitude (see also Section III.A).

\section{Typesetter to place Figure 2 here}

The quenching site Q2 is proposed to be located in a part of the LHC antenna that remains attached to the PS II core; its quenching properties presumably rely on an aggregation state induced by lowering of the luminal $\mathrm{pH}$ and further depends on the thylakoid membrane lipid environment as shown in vitro (Gundermann and Büchel 2012) and on the binding of Dd-Dt (Miloslavina et al. 2009). The quenching Q1 is proposed to be located in a part of the LHC antenna that disconnects from PS II upon illumination and forms oligomeric FCP 
complexes (potentially including both Lhcf and Lhcx proteins, see below) (Miloslavina et al. 2009). The quenching property of Q1 appears to be relatively independent of the presence of Dd-Dt in vitro (Gundermann and Büchel 2012). Chl $a_{710-712}$ oligomeric FCP complexes are already present in dark- and low light-adapted cells (Miloslavina et al. 2009; Chukhutsina et al. 2013; Lavaud and Lepetit 2013). However, until the latter disconnect from PS II, their dissipative property remains negligible. Presence of large and stable Chl $a_{710-712}$ FCP oligomers in high NPQ, dark-acclimated cells, might be induced by the decrease of the thylakoid lipid ratio MGDG/SQDG (Lepetit et al. 2012). We propose that disconnection of Chl $a_{710-712}$ FCP oligomers upon illumination is generated by both protonation of the Lhcf/Lhcx proteins involved in NPQ (Goss et al. 2006; Lavaud and Kroth 2006) and conversion of Dd to Dt (see below and Enriquez et al. 2010). Once disconnected, the Chl $a_{710-}$ 712 FCP oligomers show a spatial arrangement of pigment-protein complexes that establishes new Chl $a$-Chl $a$ interactions reducing the lifetime of excited Chl $a$ (Miloslavina et al. 2009), thereby dissipating excessive excitation energy as heat at the Q1 site in addition to the Q2 site. Recent data obtained in P. tricornutum support such a mechanism; they revealed that FCP macrodomains undergo a fast and reversible light-induced reorganization that correlates with the kinetics of NPQ (Szabo et al. 2008).

The exact regulatory role of Dt remains under debate; two alternatives have been proposed that are not mutually exclusive (Fig. 2; Enriquez et al. 2010; see also Holzwarth and Jahns Chap. 5): (1) direct quenching of excited Chl $a$ at the Q2 site by Dt via a transfer of energy from the respective $\mathrm{S}_{1}$ states of Chl $a$ and Dt as measured in vitro, or (2), together with proton binding, de-epoxidation of Dd to Dt could support a conformational change of the DdDt-binding Lhcf/Lhcx proteins, thereby promoting disconnection of the FCP oligomers and formation of the Q1 site. The latter possibility (2) is supported by (i) the sensitivity of the $\Delta 522$-nm fingerprint to the $\Delta \mathrm{pH}$-uncoupler $\mathrm{NH}_{4} \mathrm{Cl}$ and to the $\mathrm{Dd}$ de-epoxidation-inhibitor 
dithiothreitol (DTT) and (ii) numerous studies that succeeded in uncoupling $\Delta \mathrm{pH}$, Dt and NPQ in several pennate and centric species (Lavaud et al. 2002b; Goss et al. 2006a; Lavaud and Kroth 2006; Grouneva et al. 2009; Cruz et al. 2011; Gundermann and Büchel 2012; Lavaud et al. 2012). The latter studies showed three essential features of NPQ in diatoms: (1) a certain magnitude of the $\Delta \mathrm{pH}$ is needed for complete induction of NPQ, (2) NPQ can be modulated to a certain extent by $\mathrm{Dt}$ in the absence of a $\Delta \mathrm{pH}$, once $\mathrm{Dt}$ had been synthesized in the presence of a $\Delta \mathrm{pH}$, and (3) Dt is mandatory for NPQ. The possibility of a coupling between both a direct and an indirect effect of Dt in NPQ is consistent with the synergistic effect of $\Delta \mathrm{pH}$ and $\mathrm{Z}$ in the NPQ/qE allosteric model of vascular plants (Jahns and Holzwarth 2012; Ruban et al. 2012). Nevertheless, a significant part of NPQ can be maintained in the dark without any $\Delta \mathrm{pH}$ as long as Dt is present (Goss et al. 2006a; Lepetit et al. 2013), see also Section II.A.1).

The persistence of Dt in the dark was proposed to be responsible for keeping the FCP oligomers in an aggregated state (Goss et al. 2006a). The latter feature would be in line with the persistence of part of the quenching at the Q2 (and/or Q1) site(s) in the dark, i.e. as long as the majority of the Dt molecules are not converted back to Dd, the FCP oligomers cannot reconnect to PS II (Fig. 2). Retention of Dt and its engagement in thermal energy dissipation resulting in sustained NPQ in the dark were reported for several species, including pennate and centric representatives (Goss et al. 2006a; Lavaud and Lepetit 2013). Because its dark relaxation is slow, this sustained component of NPQ, also called "dark NPQ" (see Section III.B), probably contributes in part to qI, together with photo-damage/-inactivation of PS II (Wu et al. 2012). Sustained "dark NPQ" is often observed after a prolonged exposure to excess light (Lavaud and Lepetit 2013), which exhausts the pool of NADPH+ $\mathrm{H}^{+}$and leads to a slower epoxidation of Dt back to Dd in the dark (Goss et al. 2006a). Hence, at least part of the "dark NPQ" could be interpreted as a slow recovery from the light-dependent reversible 
reorganization of the LHC system. "Dark NPQ" is also observed after a prolonged exposure to darkness (several hours), where it is induced by Dt molecules generated by a chlororespiratory $\Delta \mathrm{pH}$ (see Section II.C).

The identity of the proteins involved in formation of the Q1 and Q2 sites remains unclear. These proteins are obviously different among diatom species (see Büchel, Chap. 11 for further details). In the centric diatom C. meneghiniana, the basic organizational units of FCPs are trimers $(\mathrm{FCPa})$ and hexamers $(\mathrm{FCPb})$ composed of different Lhcf/Lhcx polypeptides. Their respective features (binding of $\mathrm{Dd}$ and $\mathrm{Dt}$, ability to aggregate, dependence of the quenching property on $\mathrm{pH}$ and $\mathrm{Dt}$ ) support the possible identification of FCPa as Q2 and FCPb as Q1 (Miloslavina et al. 2009; Gundermann and Büchel 2012; Lepetit et al. 2012), although such a proposal remains to be further evaluated. In the pennate diatom P. tricornutum, a clear differentiation between FCP fractions that form trimers or hexa- to nonameric complexes (termed "FCPo") does not exist (Lepetit et al. 2007, 2010; Joshi-deo et al. 2010). FCPa contains the Fcp6 polypeptide, a member of the Lhcx family (Gundermann and Büchel, 2012), the functional ortholog of LHCSR in green algae (Niyogi and Truong 2013 and see also Morosinotto and Bassi, Chap 14; Finazzi and Minagawa, Chap. 21), termed Lhcx1 in P. tricornutum. It was proposed that Fcp6 may interact with Fcp2, a member of the Lhcf family, to form a quenching center (Gundermann and Büchel 2012) that we hypothesize to be Q2. While Fcp2 might be responsible for the $\mathrm{pH}$ sensitivity of FCPa (Gundermann and Büchel 2012), and could therefore drive the above-mentioned aggregation of FCPs at the Q2 site, the role of Fcp6/Lhcx1 remains unclear. While the latter complexes' ability to bind protons has not been completely confirmed, they appear to bind Dt (Lepetit et al. 2010; Zhu and Green 2010; Gundermann and Büchel 2012).

It has recently been demonstrated that the transcription of some Lhcx genes is coregulated with the Dd+Dt content via the redox state of the PQ pool (Lepetit et al. 2013). In $P$. 
tricornutum, an increase, via genetic engineering, of the in-vivo Lhcx1 level generates a higher NPQ (Bailleul et al. 2010; Depauw et al. 2012). Zhu and Green (2010) proposed a structural role for Lhcx1 that fits well with its presence in significant amounts in low lightacclimated cells (Bailleul et al. 2010; Schellenberger et al. 2013; Lepetit et al. 2013). Nevertheless, this proposal is not in contradiction with Lhcx 1 providing Dd- and Dt-binding sites or the amount of Dd and -Dt bound to the LHC system being modulated by the amount of Lhcx 1 as a function of strains/species and of the organism's acclimation to light (Lavaud and Lepetit 2013). There is currently no information on the Lhcf/Lhcx composition of the FCP oligomers responsible for Chl $a_{710-712}$.

In addition to Dt-dependent NPQ, part of the thermal dissipation of the excessive excitation energy can be independent of Dt synthesis. The latter NPQ is a PS II reaction center-type quenching, may include recombination of $\mathrm{Q}_{\mathrm{A}}{ }^{-}$and the $\mathrm{S} 2 / \mathrm{S} 3$ state of the oxygenevolving complex (OEC) (Eisenstadt et al. 2008), and is most likely caused by an excess light-induced structural change of the PS II core complex itself. Earlier measurements (Lavaud et al. 2002c; Feikema et al. 2006) revealed the existence of cyclic electron flow within PS II that includes an electron transfer pathway from the acceptor to the donor side (Lavaud 2007). This process has been interpreted as a protection mechanism against acceptor side photoinhibition in the OEC and donor side photoinhibition in PS II where OEC is temporarily disabled.

\section{Brown Algae}

Little is known about the mechanism of xanthophyll-dependent NPQ in brown algae (Enriquez and Borowitzka 2011). Although the latter algae display a different XC (see Section II.A.2), it seems that the NPQ of brown algae shows similar features to that of diatoms. As observed for diatoms, NPQ is mainly composed of the qE component, as a 
wavelength-dependent qT seems to be absent (Fork et al. 1991). However, the possibility of an excess light-dependent $\mathrm{qT}$ in brown algae has yet to be studied systematically. Also similar to the situation in diatoms, $\Delta \mathrm{pH}$ alone cannot generate NPQ (Lavaud et al. 2002b; Lavaud and Kroth 2006); NPQ requires the concomitant binding of A and Z to the LHC system (GarciaMendoza and Colombo-Pallotta 2007; Garcia-Mendoza et al. 2011). The relationship between NPQ and Z (and A) is similar to that of diatoms, demonstrating an obligatory role of $\mathrm{Z}$ and $\mathrm{A}$ (Garcia-Mendoza and Colombo-Pallotta 2007; Ocampo-Alvarez et al. 2013). Strikingly, this relationship depends on light acclimation and the size of the VAZ pool (Ocampo-Alvarez et al. 2013), as is also the case in diatoms (Schumann et al. 2007). Because NPQ in brown algae reacts as in diatoms to DTT, $\Delta \mathrm{pH}$ uncouplers $\left(\mathrm{NH}_{4} \mathrm{Cl}\right.$, nigericin), and shows the same differences in pre-illuminated versus dark-adapted samples (Garcia-Mendoza and ColomboPallotta 2007; Garcia-Mendoza et al. 2011), it is likely to display similar mechanistic features as well (see Section 2.B.1).

Alternatively, NPQ in brown algae was proposed to depend only on the synthesis of $\mathrm{Z}$ and $\mathrm{A}$, and thus would be controlled by the activity of the XC enzymes and by the number of quenching sites in the light-harvesting complex (Ocampo-Alvarez et al. 2013). Such a $\Delta \mathrm{pH}-$ independent but Z- and A-dependent NPQ would be comparable to the slowly reversible, $\mathrm{pH}$ independent form of NPQ in evergreen vascular plants persisting throughout harsh seasons (Demmig-Adams et al. 2006; see also Demmig-Adams et al., Chap. 24). In general, it can be concluded that the considerable NPQ observed in some diatoms (Lavaud et al. 2002a; Ruban et al. 2004) and brown algae (Garcia-Mendoza and Colombo-Pallotta 2007) is independent of the specific nature of the XC pigments, i.e. Dt or Z and A. Instead, NPQ most likely depends on the ability to synthesize a large amount of either Dt or Z and A (Lavaud et al. 2003; Garcia-Mendoza and Colombo-Pallotta 2007) and on the spatial organization and the protein composition of the FCP complexes (Lavaud 2007; see Section II.A.1). 
The Lhcf/Lhcx proteins involved in thermal energy dissipation and thus NPQ in brown algae have not been identified yet. However, the recent sequencing of the Ectocarpus silicosus genome highlighted their large diversity with about 40 Lhcf genes and 13 Lhcx genes (Dittami et al. 2010). Interestingly, and comparable to the situation in diatoms, an FCP complex with a high content of XC pigments exists (De Martino et al. 1997, 2000); it most likely is one of the NPQ sites (Q2). In M. pyrifera, a large VAZ pool is found in blades growing at the surface and exposed to high and changing light conditions (Ocampo-Alvarez et al. 2013). This is concomitant with a higher expression of two LI818 isoforms ("LHC7" and "LHC8") (Konotchick et al. 2013), as the functional orthologs of the diatom Lhcx and the green algal LHCSR (Niyogi and Truong 2013 and see also Morosinotto and Bassi, Chap 14; Finazzi and Minagawa, Chap. 21). It is thus very likely that LI818 proteins are involved in the NPQ process in brown algae, although a thorough biochemical investigation is needed to decipher their exact role.

\section{Regulation of Xanthophyll Cycle-Dependent NPQ}

Because Dt and Z are mandatory for NPQ in diatoms and brown algae, respectively, the most important factors for regulation of the majority of energy dissipation underlying NPQ are the kinetics of the build-up and relaxation of the $\Delta \mathrm{pH}$ and the availability of the co-substrates of the de-epoxidation and epoxidation reactions (summarized in Fig. 1). In general, Dd deepoxidation is faster than the respective conversion of $\mathrm{V}$ to $\mathrm{A}$ and $\mathrm{Z}$ in vascular plants and brown algae (Lavaud et al. 2002b; Goss et al. 2006a). The faster kinetics are caused by the almost immediate activation of DDE due to the shift of its $\mathrm{pH}$-optimum to higher $\mathrm{pH}$-values (Jakob et al. 2001). This shift is accompanied by complete inhibition of Dt epoxidation by establishment of the $\Delta \mathrm{pH}$ (Mewes and Richter 2002; Goss et al. 2006a; see also Section II.A.1). Rapid Dd de-epoxidation correlates with a very fast induction of NPQ (Lavaud et al. 
2002; Lavaud and Kroth 2006). The almost immediate generation of NPQ is further aided by the existence of an NPQ component that shows extremely fast kinetics after the onset of illumination (Grouneva et al. 2008). This component relies on establishment of the $\Delta \mathrm{pH}$ and depends on the concentration of Dt already present at the onset of illumination (Lavaud and Kroth 2006; Grouneva et al. 2008). A comparably fast NPQ component that depends on the presence of $\mathrm{Z}$ at the onset of actinic illumination has also been observed in vascular plants (Demmig-Adams et al. 1989; Kalituho et al. 2007; see also Demmig-Adams et al., Chap 24).

Due to the prominent differences in the $\mathrm{pH}$-dependent activation of DDE of diatoms and VDE of vascular plants, low pH-gradients are already sufficient to activate DDE of diatoms (see Section II.A.1). This means that, in addition to light-dependent DDE activation, Dd de-epoxidation can also be triggered by a chlororespiratory $\Delta \mathrm{pH}$ in the dark (Jakob et al. 1999, 2001; Cruz et al. 2011). Although establishment of a $\Delta \mathrm{pH}$ by chlororespiration is rather slow, significant synthesis of Dt occurs during prolonged periods of darkness. In $P$. tricornutum, accumulation of Dt is further supported by inhibition of DEP by the chlororespiratory $\Delta \mathrm{pH}$ (Cruz et al. 2011). Dt epoxidation is also limited when the co-substrate of DEP, NADPH, is not available in sufficient concentration. Such a partial inhibition of Dt epoxidation occurs during dark periods that follow excess light illumination (Goss et al. 2006a). It was proposed that both the ongoing Calvin-Benson Cycle and the chlororespiratory electron flow act as sinks for NADPH, thereby depriving DEP of its cosubstrate (Grouneva et al. 2009). In contrast, the conversion of Dt to Dd is very fast and efficient after a transition from high to low light (Goss et al. 2006a; Grouneva et al. 2009), probably because electron transport is sufficient to generate the NADPH needed for Dt epoxidation. Both the fast deprivation of NADPH during dark periods following excess light illumination and the maintenance of NADPH synthesis during low light illumination is in line with the assumption 
that diatoms contain a significantly smaller pool of $\mathrm{NADP}^{+} / \mathrm{NADPH}$ compared to vascular plants (Goss et al. 2006; Grouneva et al. 2009).

The synthesis of Dt in darkness results in the establishment of NPQ (Jakob et al. 1999, 2001; Cruz et al. 2011). However, the quenching efficiency of Dt generated by a chlororespiratory $\Delta \mathrm{pH}$ may be lower than that of Dt formed by a light-driven $\Delta \mathrm{pH}$ (Cruz et al. 2011). In Thalasiosira pseudonana, a high concentration of Dt can be induced in the dark by anaerobic conditions without development of a correspondingly high NPQ (Cruz et al. 2011). The return to aerobic conditions strongly increases the quenching efficiency of Dt, most likely by a significant increase of lumen acidification via a combination of electron transport from the plastoquinone (PQ) pool to oxygen by PQ oxidase and proton translocation by a type-1 $\mathrm{NAD}(\mathrm{P}) \mathrm{H}$ dehydrogenase (Ndh) (Cruz et al. 2011).

Chlororespiration also contributes to Dt synthesis and NPQ during excess light illumination (Eisenstadt et al. 2008; Grouneva et al. 2009). This, however, depends on the diatom species (Grouneva et al. 2009). The complete inhibition of light-driven linear electron transport by DCMU in $P$. tricornutum does not lead to a breakdown of $\Delta \mathrm{pH}$. In contrast, electron flow from the stroma to the PQ pool and the PQ oxidase, in combination with a type$1 \mathrm{Ndh}$, maintains a chlororespiratory $\Delta \mathrm{pH}$ that leads to further Dd de-epoxidation and NPQ (see above). Since this latter electron flow is not coupled to $\mathrm{NADP}^{+}$reduction, the substrate of DEP is not synthesized, thus restricting a competing epoxidation of Dt to Dd. In the diatom $C$. meneghiniana, the first steps of the alternative electron flow are comparable and also result in donation of electrons from stromal sources to the PQ pool. Further electron transfer reactions are, however, different and include electron transport from the PQ pool to PS I, which results in the production of NADPH. Chlororespiratory electron transport in C. meneghiniana does not lead to the generation of a $\Delta \mathrm{pH}$, most likely due to the absence of electron donation to PQ oxidase and due to involvement of a type- $2 \mathrm{Ndh}$ that does not translocate protons. 
Consequently, chlororespiratory-dependent Dd de-epoxidation and NPQ is not observed as long as the generation of NADPH simultaneously enables epoxidation of preformed Dt to Dd.

\section{Importance of the Xanthophyll Cycle and NPQ in the Field}

\section{A. Diatoms of the Phytoplankton}

Planktonic diatoms live in a three-dimensional environment characterized by strong physical driving forces coupled with a depth-dependent attenuation of the irradiance. They usually undergo passive movements determined by their sinking rate and the water turbulence. Many studies have explored the in-situ functioning of the XC and NPQ in planktonic diatoms in different ecosystems and in relation to changes of the diurnal, seasonal, and latitudinal underwater light climate (see Brunet and Lavaud 2010). On a yearly scale, the pool size of Dd+Dt, the extent of Dd de-epoxidation, and NPQ correlate well with day length and seasonal changes in irradiance. On a daily scale, Dt and NPQ track the course of the sun and the water depth, showing an increase at midday and in the upper layer of the water column. In that framework, the dynamics of the Dd+Dt pool size and Dt synthesis were often used to characterize the coupling of phytoplankton photosynthesis with light and hydrodynamics. While changes in the pool size of $\mathrm{Dd}+\mathrm{Dt}$ provide information on the average irradiance to which the diatom cells have been exposed during the past hours/days, the dynamics of Dt synthesis can be used as a tracer for cell movements within the euphotic zone (Brunet and Lavaud 2010; Hashihama et al. 2010). The dynamics of the XC and NPQ, together with other physiological processes (MacIntyre et al. 2000), thus appear relevant for the regulation of the photosynthetic productivity of planktonic diatoms in the mixed upper layer of the water column, especially in the context of a regular exposure to excessive light intensities (Alderkamp et al. 2010; Brunet and Lavaud 2010) coupled with other environmental stresses (Petrou et al. 2011) and during bloom conditions (Fujiki et al. 2003). 
Planktonic diatoms, and to a larger extent planktonic microalgae, show a large intergroup/species XC and NPQ diversity (Lavaud et al. 2007; Brunet and Lavaud 2010; Goss and Jakob 2010). It was proposed that the XC-NPQ activity and efficiency may be influenced by ecological niche adaptation, i.e. the light environment of the habitat from which the strains/ecotypes originate (Lavaud 2007; Brunet and Lavaud 2010). In other words, the XC and NPQ efficiency would be a functionally adaptive trait that would participate in the cost/benefit balance of photoadaptative strategies (McKew et al. 2013) and that could, in part, explain the geographical/spatial species distribution and their temporal succession (Lavaud 2007; Brunet and Lavaud 2010). Dimier et al. (2009) even proposed a classification of ecological groups of phytoplankton based on their XC dynamics.

The hypothesis of XC and NPQ as functional traits was investigated by a comparison of representatives of the main phytoplankton groups (Casper-Lindley and Bjorkman 1998; Meyer et al. 2000; van Leeuwe et al. 2005; Wagner et al. 2006; Kropuenske et al. 2009; van de Poll et al. 2011). In general, diatoms seem to cope well with a fluctuating light climate, i.e. they can exert strong NPQ (Lavaud et al. 2002a; Ruban et al. 2004; Lavaud 2007). This feature is an adaptive advantage in deeply-mixed aquatic habitats: it drives, in part, the competition for light among phytoplankton groups that ultimately participate in species succession independent of other environmental cues (Huisman et al. 2004; Edwards et al. 2013). Interestingly, it has been debated how modifications of upper-ocean turbulence may have shaped the functional and evolutionary ecology of planktonic diatoms and may currently influence their geographical distribution (Falkowski et al. 2004; Tozzi et al. 2004). The ecophysiological connection to XC-NPQ diversity of planktonic diatoms was investigated by comparing strains/ecotypes from different pelagic habitats (estuary, coast, semi-enclosed bay, open ocean) (Lavaud et al. 2004, 2007; Strzepek and Harrison 2004; van de Poll et al. 2006; Petrou et al. 2011), including different seasonal distributions (Dimier et al. 2007) and pico- 
phytoplankton representatives (Giovagnetti et al. 2012). A special focus was recently given to diatom representatives of polar ecosystems (van Leeuwe et al. 2005; van de Poll et al. 2006, 2011; Kropuenske et al. 2009; Mills et al. 2010; Petrou et al. 2011). Species/ecotypes adapted to a more stable light environment (semi-enclosed bays/open ocean versus estuaries/coasts) seem to rely more on regulatory processes other than NPQ and the PS II electron cycle (see Section II.B.1), which are likely better suited to cope with more gradual light changes: (1) a fast turnover of the PS II D1 protein (Wu et al. 2012; Lavaud J. and Campbell D. unpublished results 2013), and (2) employment of Dt in the prevention of lipid peroxidation (Lepetit et al. 2010; Lavaud and Lepetit 2013). Finally, the adjustment of light harvesting pigment content (Brunet et al. 2011) and of the metabolic capacity, and especially the balance of energy between lipids and carbohydrates, is of importance for the response to dynamic light regimes of diatoms with different NPQ capacity (Su et al. 2012).

A recent report suggested a molecular basis for the diversity in NPQ capacity observed among planktonic diatoms based on the mechanistic model described in Section II.B.1 (Lavaud and Lepetit 2013). A high capacity for NPQ seems to depend on a large amount of Dt present at the Q2 quenching site (see Figure 2) and the capacity to form many/large Q1 quenching sites (Lavaud and Lepetit 2013). In addition, the number of Lhcx proteins present in the light-harvesting system seems to be crucial (Bailleul et al. 2010; Zhu and Green 2010; Lepetit et al. 2013). NPQ capacity is based more on the plastidic distribution of Dt and its effective involvement in NPQ than on the total amount of Dd+Dt and the de-epoxidation state of the XC (DES), i.e. species/ecotypes can show the same Dd+Dt content and DES with a drastically different NPQ amplitude and kinetics (Lavaud and Lepetit 2013). For that reason, the slope of the relationship between Dt and NPQ appears to be a good indicator of the adaptation of diatom species/ecotypes to a specific light regime and, possibly, an aquatic niche (Lavaud et al. 2004, 2007; Lavaud and Lepetit 2013). 


\section{B. Diatoms of the Microphytobenthos}

The in-situ light response of diatoms of the microphytobenthic (MPB) community has received less attention. This is probably due to the technical challenge of measuring the photosynthetic activity of the MPB community in its major natural habitat, i.e. estuarine mudflats (though MPB organisms can also be found in surf beaches, coral reef lagoons, and shallow coastal waters) (Underwood and Kromkamp 1999; Perkins et al. 2011). Because they inhabit sediments, MPB diatoms experience a different light climate than planktonic diatoms. The fluctuations of irradiance at the surface of mudflats are similar to those on a land surface, with the succession of emersion/immersion periods adding a regular, sharp light/dark photoperiod. Additionally, other environmental cues (especially temperature and salinity) can vary rapidly between extremes (Underwood and Kromkamp 1999) and generate stressful conditions.

The in-situ pool size of Dd+Dt and XC operation in the MPB diatoms depends strongly on light and temperature as a function of the tidal cycle, season, and latitude (van Leeuwe et al. 2009; Chevalier et al. 2010; Jordan et al. 2010). The DES correlates well with higher daily and latitudinal irradiances (van Leeuwe et al. 2009; Chevalier et al. 2010; Jordan et al. 2010) and with light distribution in the sediments, i.e. a higher DES is observed at the surface (Jesus et al. 2009; Cartaxana et al. 2011). The NPQ of the MPB diatoms in situ can reach high values above 5-6 (Serôdio et al. 2005, 2008, 2012). In general, NPQ correlates well with DES with an especially clear increase at midday emersion (exposure to high irradiance) in summer (Serôdio et al. 2005; Chevalier et al. 2010). The seasonal pattern of NPQ is strongly influenced by both irradiance and temperature in a complex manner (Serôdio et al. 2005, 2012; Jesus et al. 2006). These general trends of light and temperature control 
were also reported for isolated benthic diatoms (Perkins et al. 2006; Salleh and McMinn 2011; Serôdio and Lavaud 2011).

Of considerable interest are differences in the ability of species/groups to cope with excessive light/UV exposure (Waring et al. 2006; Jesus et al. 2009; Cartaxana et al. 2011), which is similar to the situation in planktonic diatoms (see Section III.A). Differences in adaptation are believed to potentially impact spatial distribution (muddy versus sandy habitats) as well as species succession within the MPB biofilm during emersion and different seasons (Tuji 2000; Serôdio et al. 2005; Underwood et al. 2005). Epipsammic species (firmly attached to sediment particles) use physiological processes such as the $\mathrm{XC}$ and energy dissipation underlying NPQ for their photoprotection (Jesus et al. 2009; Cartaxana et al. 2011). Epipelic (freely living in sediment particles) motile species rely on both physiology and "behavioral photoprotection", i.e. the cells use their vertical mobility to escape from excess light (Consalvey et al. 2004; Perkins et al. 2010).

The respective importance of physiological and behavioral photoprotection has long been a topic of interest and has shown major recent advances (Jesus et al. 2006; Mouget et al. 2008; Perkins et al. 2010; Cartaxana et al. 2011; Serôdio et al. 2012). In general, both XCdependent photoprotection and behavioral photoprotection provide the MPB diatoms with a strong capacity to resist periods of prolonged excessive light (Blanchard et al. 2004; Serôdio et al. 2008, 2012; Perkins et al. 2010), including strong resistance to UV radiation (Waring et al. 2007; Mouget et al. 2008). Additionally, MPB diatoms are usually characterized by a strong “dark NPQ" (Perkins et al. 2011) (see Section II.B.1), which presumably allows the cells to maintain their antenna system in a basal dissipative state and fully activate their NPQ machinery more rapidly upon sudden light exposure. Such a system would be especially relevant for the MPB diatoms that can spend more than $18 \mathrm{~h}$ per day in the dark (immersion and night emersion) before being exposed to sunlight again. 


\section{Brown Algae}

Because most of the main macrophytic brown algae are sessile organisms, their light environment strongly depends on the water depth where they are located. The light environment of immerged brown algae is similar to that of planktonic diatoms at a given depth, while the light environment of emerged thalli bears greater semblance to that of the benthic diatoms. Brown algae are able to perform XC-dependent energy dissipation reflected in NPQ, with high NPQ reported for some species adapted to harsh environments, i.e. species living at the air-water interface and in the upper zone of the intertidal rocky shore (Harker et al. 1999; Colombo-Pallotta et al. 2006). Increases in XC carotenoid levels, conversion of those carotenoids to the forms responsible for energy dissipation, and their engagement in energy dissipation underlying NPQ are involved in the response to natural irradiance changes, including excessive light exposure and UV radiation (Uhrmacher et al. 1995; Hanelt et al. 1997; Schofield et al. 1998; Apprill and Lesser 2003), sometimes coupled with other environmental stresses, especially desiccation (Harker et al. 1999) and high temperature (Poulson et al. 2011). For the same individual, the level of XC-dependent NPQ can be diverse among different parts of the thallus, dependent on the respective age of the thallus parts (Colombo-Pallotta et al. 2006; Poulson et al. 2011) as well as life-cycle stage (sporophytes versus gametophytes) (Hanelt et al. 1997). For instance, in Laminaria saccharina, gametophytes are more resistant to excessive light stress than sporophytes, partially due to a stronger XC, which may influence their respective distribution on the sea shore (Hanelt et al. 1997).

The zonation of brown macroalgal species strongly depends on their depth distribution in and out of the water column (depending on the tide) as a function of irradiance and the light climate, with the exception of pelagic species like Sargassum spp. (Schofield et al. 1998). 
Inter-species XC-NPQ variability correlates with depth distribution, showing a higher NPQ capacity for the species located on the upper-shore (Harker et al. 1999; Rodrigues et al. 2002; Nitschke et al. 2012). In this case, the higher NPQ capacity (usually twice as high) correlates with an increase of the pool size of VAZ and a greater synthesis of Z (Harker et al. 1999; Rodrigues et al. 2002). The depth distribution and the related XC-dependent NPQ acclimation to irradiance also holds true for the same species in a given ecosystem (Apprill and Lesser 2003). All intertidal species increase the level of NPQ during emersion; for instance, the acclimative response of $L$. digitata to midday emersion involves $\mathrm{Z}$ synthesis and increased NPQ resulting from increased thermal energy dissipation (Gévaert et al. 2002, 2003; Apprill and Lesser 2003). Laminaria digitata also exhibits a XC-NPQ seasonal pattern involving an increase of the VAZ pool size in spring compared to winter (Gévaert et al. 2002). The canopy-forming Macrocystis pyrifera provides a striking example (Colombo-Pallotta et al. 2006; Konotchick et al. 2013; Ocampo-Alvarez et al. 2013). Due to its height (about 18-20 m), this alga occupies the entire water column, such that the blades close to the surface are exposed to an underwater light environment with higher irradiance and stronger fluctuations. Within a single organism, the XC-dependent capacity for NPQ varies dramatically with depth (5-fold), with NPQ values being linearly related to water depth. As is also the case for intertidal species, NPQ differences are correlated with VAZ pool size and the capacity to synthesize $\mathrm{Z}$ and $\mathrm{A}$, and with the differential expression of LI818 isoforms (Colombo-Pallotta et al. 2006; Konotchick et al. 2013; Ocampo-Alvarez et al. 2013). Finally, in pelagic species that live at the air-surface interface, the XC conversions follow the daily course of the sun and NPQ strictly correlates with the synthesis and the accumulation of Z (Schofield et al. 1998).

Interestingly, the strongest competitors with brown algae in the intertidal zone are the red algae (Wiencke and Bischof 2012). Based on the current state of knowledge, it is not clear if red algae contain an operable XC (Carnicas et al. 1999; Ursi et al. 2003). Despite this 
ongoing debate (Goss and Jakob 2010), red algae are characterized by a high, stable concentration of $\mathrm{Z}$, thus demonstrating the importance of de-epoxidized xanthophylls for efficient photoprotection.

\section{Conclusion}

Investigations of the XC and photoprotective thermal energy dissipation (as reflected in NPQ) in diatoms and brown algae are of high importance for two obvious reasons: (1) the algae are essential primary producers in marine ecosystems, and, (2) their productivity is based mainly on light availability that can fluctuate drastically in aquatic habitats. XC-dependent energy dissipation (NPQ) appears to be the central mechanism for the rapid adjustment of light harvesting and photochemistry of the cell, thereby enabling diatoms and brown algae to maintain an optimal productivity in a permanently changing light environment. The most recent advances provide new insights into the regulation of the $\mathrm{XC}$ and the underlying mechanism of NPQ (Goss and Jakob 2010; Depauw et al. 2012; Lepetit et al. 2012, 2013) and the species/strain diversity of the XC and NPQ, including the latter features' potential ecophysiological importance (Brunet and Lavaud 2010; Petrou et al. 2011; Lavaud and Lepetit 2013). There are numerous areas that deserve further attention in the near future, starting with the investigation of the protein partners involved in the regulation of NPQ (especially the Lhcx proteins and the Chl $a_{710-712}$ FCP complexes) and experiments to confirm the importance of the XC-dependent process(es) underlying NPQ as a functional trait essential to the ecology of diatoms and brown algae. To further investigate the latter, more thorough in-situ studies are needed that take advantage of recent improvements in fluorescence methodology and analysis of NPQ (Perkins et al. 2011; Enriquez and Borowitzka 2011; Lefebvre et al. 2011; Serôdio and Lavaud 2011; Nitschke et al. 2012). To gain further knowledge about the mechanistic basis of NPQ in diatoms and brown algae, genomic/genetic tools in conjunction with 
sophisticated spectroscopic and physiological measurements will have to be performed. While such approaches have already shown their utility in diatoms (Materna et al. 2009; Bailleul et al. 2010; Depauw et al. 2012; Lavaud et al. 2012; Lepetit et al. 2013), this field has just opened up for brown algae (Dittami et al. 2010; Konotchick et al. 2013).

\section{Acknowledgments}

JL thanks the Centre National de la Recherche Scientifique (CNRS), the Universite de La Rochelle (ULR), the Contrat Plan Etat Région (CPER) 'Littoral', the Région PoitouCharentes (CG17), the Deutsche Forschungsgemeinschaft (DFG, grant LA2368/2-1), the Deutscher Akademischer Austausch Dienst (DAAD), and Egide/Campus France (grants 27377TB and 28992UA) for their financial support. RG thanks the DFG (grants Go818/6-1, Go818/7-1) for its financial support. The two authors thank B. Lepetit for his help building and drawing the model of Figure 2. JL dedicates this work to his mentors Pr. J.-C. Duval and Dr. A.-L. Etienne.

\section{References}

Adams WW III, Demmig-Adams B (1992) Operation of the xanthophyll cycle in higher plants in response to diurnal changes in incident sunlight. Planta 186: 390-398

Alderkamp A-C, de Baar HJW, Wisser RJW, Arrigo KR (2010) Can photoinhibition control phytoplankton abundance in deeply mixed water columns of the Southern Ocean? Limnol Oceanogr 55: 1248-1264

Apprill AM, Lesser MP (2003) Effects of ultraviolet radiation on Laminaria saccharina in relation to depth and tidal height in the Gulf of Maine. Mar Ecol Prog Ser 256: 75-85

Armbrust EV (2009) The life of diatoms in the world's oceans. Nature 459: 185-192 
Arnoux P, Morosinotto T, Saga G, Bassi R, Pignol D (2009) A structural basis for the pHdependent xanthophyll cycle in Arabidopsis thaliana. Plant Cell 21: 2036-2044

Bailleul B, Rogato A, de Martino A, Coesel S, Cardol P, Bowler C, Falciatore A, Finazzi G (2010) An atypical member of the light-harvesting complex stress-related protein family modulates diatom responses to light. Proc Natl Acad Sci USA 107: 18214-18219

Blanchard G, Guarini J-M, Dang C, Richard P (2004) Characterizing and quantifying photoinhibition in intertidal microphytobenthos. J Phycol 40: 692-696

Brunet C, Johnsen G, Lavaud J, Roy S (2011) Pigments and photoacclimation processes. In: Roy S, Llewellyn CA, Skarstad E, Johnsen G (eds) Phytoplankton Pigments: Characterization, Chemotaxonomy and Applications in Oceanography, pp 445-471. Cambridge University Press, Cambridge

Brunet C, Lavaud J (2010) Can the xanthophyll cycle help extract the essence of the microalgal functional response to a variable light environment? J Plankton Res 32: 1609_ 1617

Carnicas E, Jiménez C, Niell F (1999) Effects of changes of irradiance on the pigment composition of Gracilaria tenuistipitata var. liui Zhang et Xia. J Photochem Photobiol B 50: $149-158$

Cartaxana P, Ruivo M, Hubas C, Davidson I, Serôdio J, Jesus B (2011) Physiological versus behavioral photoprotection in intertidal epipelic and epipsammic benthic diatom communities. J Exp Mar Biol Ecol 405: 120-127

Casper-Lindley C, Björkman O (1998) Fluorescence quenching in four unicellular algae with different light-harvesting and xanthophyll-cycle pigments. Photosynth Res 56: 277-289 
Chevalier EM, Gévaert F, Créach A (2010) In situ photosynthetic activity and xanthophyll cycle development of undisturbed microphytobenthos in an intertidal mudflat. J Exp Mar Biol Ecol 385: 44-49

Chukhutsina VU, Büchel C, van Amerongen H (2013) Variations in the first steps of photosynthesis for the diatom Cyclotella meneghiniana grown under different light conditions. Biochim Biophys Acta 1027: 10-18

Colombo-Pallotta MF, García-Mendoza E, Ladah LB (2006) Photosynthetic performance, light absorption, and pigment composition of Macrocystis pyrifera (Laminariales, Phaeophyceae) blades from different depths. J Phycol 42: 1225-1234

Consalvey MC, Paterson DM, Underwood GJC (2004) The ups and downs of life in a benthic biofilm: migration of benthic diatoms. Diatom Res 19: 181-202

Cruz S, Goss R, Wilhelm C, Leegood R, Horton P, Jakob T (2011) Impact of chlororespiration on non-photochemical quenching of chlorophyll fluorescence and on the regulation of the diadinoxanthin cycle in the diatom Thalassiosira pseudonana. J Exp Bot 62: $509-519$

Dambek M, Eilers U, Breitenbach J, Steiger S, Büchel C, Sandmann G (2012) Biosynthesis of fucoxanthin and diadinoxanthin and function of initial pathway genes in Phaeodactylum tricornutum. J Exp Bot 63: 5607-5612

De Martino A, Douady D, Rousseau B, Duval JC, Caron L (1997) Characterization of two light-harvesting subunits isolated from the brown alga Pelvetia canaliculata: heterogeneity of xanthophyll distribution. Photochem Photobiol 66: 190-197

De Martino A, Douady D, Quinet-Szely M, Rousseau B, Crepineau F, Apt K, Caron L (2000) The light-harvesting antenna of brown algae highly homologous proteins encoded by a multigene family. Eur J Biochem 267: 5540-5549 
De Reviers B, Rousseau F (1999) Towards a new classification of the brown algae. In: Round FE, Chapman DJ (eds) Progress in Phycological Research, Volume 13, pp 107-201. Biopress, Bristol

Demmig-Adams B, Adams WW III (2006) Photoprotection in an ecological context: the remarkable complexity of thermal energy dissipation. New Phytol 172: 11-21

Demmig-Adams B, Wiinter K, Krüger A, Czygan F-C (1989) Zeaxanthin and the induction and relaxation kinetics of the dissipation of excess excitation energy in leaves in $2 \% \mathrm{O}_{2}$, 0\% $\mathrm{CO}_{2}$. Plant Physiol 90: 887-893

Demmig-Adams B, Ebbert V, Mellman DL, Mueh KE, Schaffer L, Funk C, Zarter RC, Adamska I, Jansson S, Adams WW III (2006) Modulation of PsbS and flexible vs sustained energy dissipation by light environment in different species. Physiol Plant 127: $670-680$

Depauw FA, Rogato A, d'Alcala MR, Falciatore A (2012) Exploring the molecular basis of responses to light in marine diatoms. J Exp Bot 63: 1575-1591

Dimier C, Corato F, Tramontano F, Brunet C (2007) Photoprotective capacity as functional trait in planktonic algae: relationship between xanthophyll cycle and ecological characteristics in three diatoms. J Phycol 43: 937-947

Dimier C, Giovanni S, Ferdinando T, Brunet C (2009) Comparative ecophysiology of the xanthophyll cycle in six marine phytoplanktonic species. Protist 160: 397-411

Dittami SM, Michel G, Collén J, Boyen C, Tonon T (2010) Chlorophyll-binding proteins revisited - a multigenic family of light-harvesting and stress proteins from a brown algal perspective. BMC Evol Biol 10: 365-379

Edwards KF, Lichtam E, Klausmeier CA (2013) Functional traits explain phytoplankton community structure and seasonal dynamics in a marine ecosystem. Ecol Lett 16: 56-63 
Eisenstadt D, Ohad I, Keren N, Kaplan A (2008) Changes in the photosynthetic reaction centre II in the diatom Phaeodactylum tricornutum result in non-photochemical fluorescence quenching. Environ Microbiol 10:1997-2007

Enriquez MM, LaFountain AM, Budarz J, Fuciman M, Gibson GN, Frank HA (2010) Direct determination of the excited state energies of the xanthophylls diadinoxanthin and diatoxanthin from Phaeodactylum tricornutum. Chem Phys Lett 493: 353-357

Enriquez S, Borowitzka MA (2011) The use of the fluorescence signal in studies of seagrasses and macroalgae. In: Prasil O, Sugget D, Borowitzka MA (eds) Chlorophyll $a$ Fluorescence in Aquatic Sciences: Methods and Applications, Developments in Applied Phycology, Volume 4, pp 187-208. Springer, Dordrecht

Falkowski PG, Katz ME, Knoll AH, Quigg A, Raven JA, Schofield O, Taylor FJR (2004) The evolution of modern eukaryotic phytoplankton. Science 305: 354-360

Feikema WO, Marosvölgyi MA, Lavaud J, van Gorkom HJ (2006) Cyclic electron transfer in photosystem II in the marine diatom Phaeodactylum tricornutum. Biochim Biophys Acta 1757: 829-834

Fork DC, Herbert SK, Malkin S (1991) Light energy distribution in the brown alga Macrocystis pyrifera (giant kelp). Plant Physiol 95: 731-739

Frommolt R, Werner S, Paulsen H, Goss R, Wilhelm C, Zauner S, Maier UG, Grossman AR, Bhattacharya D, Lohr M (2008) Ancient recruitment by chromists of green algal genes encoding enzymes for carotenoid biosynthesis. Mol Biol Evol 25: 2653-2667

Fujii R, Kita M, Iinuma Y, Oka N, Takaesu Y, Taira T, Iha M, Cogdell RJ, Hashimoto H (2012) Isolation and purification of the major photosynthetic antenna, fucoxanthin-Chl a/c protein, from cultured discoid germlings of the brown alga, Cladosiphon okamuranus TOKIDA (Okinawa Mozuku). Photosynth Res 111: 157-163 
Fujiki T, Toda T, Kikuchi T, Taguchi S (2003) Photoprotective response of xanthophyll pigments during phytoplankton blooms in Sagami Bay, Japan. J Plankton Res 25: 317322

García-Mendoza E, Colombo-Pallotta MF (2007) The giant kelp Macrocystis pyrifera presents a different nonphotochemical quenching control than higher plants. New Phytol 173: $526-536$

García-Mendoza E, Ocampo-Alvarez H, Govindjee (2011) Photoprotection in the brown alga Macrocystis pyrifera: Evolutionary implications. J Photochem Photobiol B: Biology 104: $377-385$

Gévaert F, Créach A, Davoult D, Holl, A-C, Seuront L, Lemoine Y (2002) Photo-inhibition and seasonal photosynthetic performance of the seaweed Laminaria saccharina during a simulated tidal cycle: chlorophyll fluorescence measurements and pigment analysis. Plant Cell Environ 25: 859-872

Gévaert F, Créach A, Davoult D, Migné A, Levavasseur G, Arzel P, Holl A, Lemoine Y (2003) Laminaria saccharina photosynthesis measured in situ: photoinhibition and xanthophyll cycle during a tidal cycle. Mar Ecol Prog Ser 247: 43-50

Giovagnetti V, Cataldo ML, Conversano F, Brunet C (2012) Growth and photophysiological responses of two picoplanktonic Minutocellus species, strains RCC967 and RCC703 (Bacillariophyceae). Eur J Phycol 47: 408-420

Goss R, Lohr M, Latowski D, Grzyb J, Vieler A, Wilhelm C, Strzalka K (2005) Role of hexagonal structure-forming lipids in diadinoxanthin and violaxanthin solubilization and de-epoxidation. Biochemistry 44: 4028-4036 
Goss R, Pinto EA, Wilhelm C, Richter M (2006a) The importance of a highly active and $\Delta \mathrm{pH}$-regulated diatoxanthin epoxidase for the regulation of the PS II antenna function in diadinoxanthin cycle containing algae. J Plant Physiol 163: 1008-1021

Goss R, Lepetit B, Wilhelm C (2006b) Evidence for a rebinding of antheraxanthin to the light-harvesting complex during the epoxidation reaction of the violaxanthin cycle. J Plant Physiol 163: 585-590

Goss R, Latowski D, Grzyb J, Vieler A, Lohr M, Wilhelm C, Strzalka K (2007) Lipid dependence of diadinoxanthin solubilization and de-epoxidation in artificial membrane systems resembling the lipid composition of the natural thylakoid membrane. Biochim Biophys Acta 1768: 67-75

Goss R, Jakob T (2010) Regulation and function of xanthophyll cycle-dependent photoprotection in algae. Photosynth Res 106: 103-122

Grouneva I, Jakob T, Wilhelm C, Goss R (2006) Influence of ascorbate and pH on the activity of the diatom xanthophyll cycle-enzyme diadinoxanthin de-epoxidase. Physiol Plant 126: 205-211

Grouneva I, Jakob T, Wilhelm C, Goss R (2008) A new multicomponent NPQ mechanism in the diatom Cyclotella meneghiniana. Plant Cell Physiol 49: 1217-1225

Grouneva I, Jakob T, Wilhelm C, Goss R (2009) The regulation of xanthophyll cycle activity and of non-photochemical fluorescence quenching by two alternative electron flows in the diatoms Phaeodactylum tricornutum and Cyclotella meneghiniana. Biochim Biophys Acta 1787: 929-938 
Gundermann K, Büchel C (2012) Factors determining the fluorescence yield of fucoxanthinchlorophyll complexes (FCP) involved in non-photochemical quenching in diatoms. Biochim Biophys Acta 1817: 1044-1052

Hager A (1967a) Untersuchungen über die lichtinduzierten, reversiblen Xanthophyllumwandlungen an Chlorella und Spinacia oleracea. Planta 74: 148-172

Hager A (1967b) Untersuchungen über die Rückreaktionen im Xanthophyll-Cyclus bei Chlorella, Spinacia und Taxus. Planta 76: 138-148

Hanelt D, Wiencke C, Karsten U, Nultsch W (1997) Photoinhibition and recovery after light stress in different developmental and life history stages of Laminaria saccharina (Phaeophyta). J Phycol 33: 387-395

Harker M, Berkaloff C, Lemoine Y, Britton G, Young A, Duval JC, Rmiki N, Rousseau, B (1999) Effects of high light and desiccation on the operation of the xanthophyll cycle in two marine brown algae. Eur J Phycol 34: 35-42

Hashihama F, Umeda H, Hamada C, Kudoh S, Hirawake T, Satoh K, Fukuchi M, Kashino Y (2010) Light acclimation states of phytoplankton in the Southern Ocean determined using photosynthetic pigment distribution. Mar Biol 157: 2263-2278

Huisman J, Sharples J, Stroom JM, Visser PM, Kardinaal WEA, Verspagen, JMH, Sommeijer B (2004) Changes in turbulent mixing shift competition for light between phytoplankton species. Ecology 85: 2960-2970

Jahns P, Latowski D, Strzalka K (2009) Mechanism and regulation of the violaxanthin cycle: the role of antenna proteins and membrane lipids. Biochim Biophys Acta 1787: 3-14

Jahns P, Holzwarth AR (2012) The role of the xanthophyll cycle and of lutein in photoprotection of photosystem II. Biochim Biophys Acta 1817: 192-193 
Jakob T, Goss R, Wilhelm C (1999) Activation of diadinoxanthin de-epoxidase due to a chlororespiratory proton gradient in the dark in the diatom Phaeodactylum tricornutum. Plant Biol 1: 76-82

Jakob T, Goss R, Wilhelm C (2001) Unusual pH-dependence of diadinoxanthin de-epoxidase activation causes chlororespiratory induced accumulation of diatoxanthin in the diatom Phaeodactylum tricornutum. J Plant Physiol 158: 383-390

Jesus B, Perkins RG, Consalvey MC, Brotas V, Paterson DM (2006) Effects of vertical migration by benthic microalgae on fluorescence measurements of photophysiology. Mar Ecol Prog Ser 315: 55-66

Jesus B, Brotas V, Ribeiro L, Mendes CR, Cartaxana P, Paterson DM (2009) Adaptations of microphytobenthos assemblages to sediment type and tidal position. Contl Shelf Res 29: $1624-1634$

Jordan L, McMinn A, Thompson P (2010) Diurnal changes of photoadaptive pigments in microphytobenthos. J Mar Biol Ass UK 90: 1025-1032

Joshi-deo J, Schmidt M, Gruber A, Weisheit W, Mittag M, Kroth PG, Büchel C (2010) Characterization of a trieric light-harvesting complex in the diatom Phaeodactylum tricornutum built of FcpA and FcpE proteins. J Exp Bot 61: 3079-3087

Kalituho L, Beran KC, Jahns P (2007) The transiently generated non-photochemical quenching of excitation energy in Arabidopsis leaves is modulated by zeaxanthin. Plant Physiol 143: 1861-1870

Katoh T, Mimuro M, Takaichi S (1989) Light-harvesting particles isolated from a brown alga, Dictyota dichtoma. A supramolecular assembly of fucoxanthin-chlorophyll-protein complexes. Biochim Biophys Acta 976: 233-240 
Kirk JTO (2011) Light and Photosynthesis in Aquatic Ecosystems. Cambridge University Press, Cambridge

Konotchick T, Dupont CL, Valas RE, Badger JH, Allen AE (2013) Transcriptomic analysis of metabolic function in th egiant kelp, Macrocystis pyrifera, across depth and season. New Phytol 198: 398-407

Kooistra WHCF, Gersonde R, Medlin LK, Mann DG (2007) The origin and the evolution of the diatoms: Their adaptation to a planktonic existence. In: Falkowski PG, Knoll AH (eds) Evolution of Primary Producers in the Sea, pp 207-249. Elsevier Academic Press, Burlington

Kropuenske LR, Mills MM, van Dijken GL, Bailey S, Robinson DH, Welschmeyer NA, Arrigo KR (2009) Photophysiology in two major Southern Ocean phytoplankton taxa: Photoprotection in Phaeocystis antartica and Fragilaria cylindricus. Limnol Oceanogr 54: $1176-1196$

Latowski D, Kruk J, Burda K, Skrzynecka-Jaskier M, Kostecka-Gugala A, Strzalka K (2002) Kinetics of violaxanthin de-epoxidation by violaxanthin de-epoxidase, a xanthophyll cycle enzyme, is regulated by membrane fluidity in model lipid bilayers. Eur J Biochem 269: $4656-4665$

Latowski D, Kuczynska P, Strzalka K (2011) Xanthophyll cycle - a mechanism protecting plants against oxidative stress. Redox Report 16: 78-90

Lavaud J, Rousseau B, van Gorkom HJ, Etienne A-L (2002a) Influence of the diadinoxanthin pool size on photoprotection in the marine planktonic diatom Phaeodactylum tricornutum. Plant Physiol 129: 1398-1406 
Lavaud J, Rousseau B, Etienne A-L (2002b) In diatoms, a transthylakoidal proton gradient alone is not sufficient for non-photochemical fluorescence quenching. FEBS Lett. 523: $163-166$

Lavaud J, van Gorkom HJ, Etienne A-L (2002c) Photosystem II electron transfer cycle and chlororespiration in planktonic diatoms. Photosynth Res 74: 49-57

Lavaud J, Rousseau B, Etienne A-L (2003) Enrichment of the light-harvesting complex in diadinoxanthin and implications for the nonphotochemical quenching fluorescence quenching in diatoms. Biochemistry 42: 5802-5808

Lavaud J, Rousseau B, Etienne A-L (2004) General features of photoprotection by energy dissipation in planktonic diatoms (Bacillariophyceae). J Phycol 40: 130-137

Lavaud J, Kroth PG (2006) In diatoms, the transthylakoid proton gradient regulates the photoprotective non-photochemical fluorescence quenching beyond its control on the xanthophyll cycle. Plant Cell Physiol 47: 1010-1016

Lavaud J (2007) Fast regulation of photosynthesis in diatoms: mechanisms, evolution and ecophysiology. Funct Plant Sci Biotech 1: 267-287

Lavaud J, Strzepek R, Kroth PG (2007) Photoprotection capacity differs among diatoms: Possible consequences on the spatial distribution of diatoms related to fluctuations in the underwater light climate. Limnol Oceanogr 52: 1188-1194

Lavaud J, Materna A, Sturm S, Vugrinec S, Kroth PG (2012) Silencing of the violaxanthin de-epoxidase gene in the diatom Phaeodactylum tricornutum reduces diatoxanthin synthesis and non-photochemical quenching. PLoS One 7: e36806

Lavaud J, Lepetit B (2013) An explanation for the inter-species variability of the photoprotective non-photochemical chlorophyll fluorescence quenching in diatoms. Biochim Biophys Acta 1827: 294-302 
Lefebvre S, Mouget J-L, Lavaud J (2011) Duration of rapid light curves for determining in situ the photosynthetis of microphytobenthos biofilms. Aquat Bot 95: 1-8

Lepetit B, Volke D, Szabo M, Hoffmann R, Garab G, Wilhelm C, Goss R (2007) Spectroscopic and molecular characterization of the oligomeric antenna of the diatom Phaeodactylum tricornutum. Biochemistry 46: 9813-9822

Lepetit B, Volke D, Gilbert M, Wilhelm C, Goss R (2010) Evidence for the existence of one antenna-associated, lipid-dissolved and two protein-bound pools of diadinoxanthin cycle pigments in diatoms. Plant Physiol 154: 1905-1920

Lepetit B, Goss R, Jakob T, Wilhelm C (2012) Molecular dynamics of the diatom thylakoid membrane under different light conditions. Photosynth Res 111: 245-257

Lepetit B, Sturm S, Rogato A, Gruber A, Sachse M, Falciatore A, Kroth PG, Lavaud J (2013) High light acclimation in the secondary plastids containing diatom Phaeodactylum tricornutum is triggered by the redox state of the plastoquinone pool. Plant Physiol 161: 863865

Li Z, Wakao S, Fisher BB, Niyogi K (2009) Sensing and responding to excess light. Ann Rev Plant Biol 60: 239-260

Lohr M, Wilhelm C (1999) Algae displaying the diadinoxanthin cycle also possess the violaxanthin cycle. Proc Natl Acad Sci USA 96: 8784-8789

Lohr M (2011) Carotenoid metabolism in phytoplankton. In: Roy S, Llewellyn CA, Skarstad E, Johnsen G (eds) Phytoplankton Pigments: Characterization, Chemotaxonomy and Applications in Oceanography, pp 113-161. Cambridge University Press, Cambridge

Materna A, Sturm S, Kroth PG, Lavaud J (2009) First induced plastid genome mutations in an alga with secondary plastids: $p s b A$ mutations in the diatom Phaeodactylum tricornutum 
(Bacillariophyceae) reveal consequences on the regulation of photosynthesis. J Phycol 45: $838-846$

MacIntyre HL, Kana TM, Geider RJ (2000) The effect of water motion on short-term rates of photosynthesis by marine phytoplankton. Trends Plant Sci 5: 12-17

McKew BA, Davey P, Finch SJ, Hopkins J, Lefebvre SC, Metodiev MV, Oxborough K, Raines CA, Lawson T, Geider RJ (2013) The trade-off between the light-harvesting and photoprotective functions of fucoxanthin-chlorophyll proteins dominates light acclimation in Emiliana huxleyi (clone CCMP 1516). New Phytol DOI: 10.1111/nph.12373

Mewes H, Richter M (2002) Supplementary ultraviolet-B radiation induces a rapid reversal of the diadinoxanthin cycle in the strong light-exposed diatom Phaeodactylum tricornutum. Plant Physiol 130: 1527-1535

Meyer AA, Tackx M, Daro N (2000) Xanthophyll cycling in Phaeocystis globosa and Thalassiosira sp.: a possible mechanism for species succession. J Sea Res 43: 373-384

Mills MM, Kropuenske LR, van Dijken GL, Alderkamp A-C, Berg GM, Robinson DH, Welschmeyer NA, Arrigo, KR (2010) Photophysiology in two Southern ocean phytoplankton taxa: Photosynthesis of Phaeocystis antarctica (Prymnesiophyceae) and Fragilaria cylindrus (Bacillariophyceae) under simulated mixed-layer irradiance. J Phycol 46: $1114-1127$

Mouget J-L, Perkins RG, Consalvey M, Lefebvre S (2008) Migration or photoacclimation to prevent high irradiance and UV-B damage in marine microphytobenthic communities. Aquat Microb Ecol 52: 223-232

Moustafa A, Beszteri B, Maier UG, Bowler C, Valentin K, Bhattacharya D (2009) Genomic footprints of a cryptic plastid endosymbiosis in diatoms. Science 324: 1724-1726 
Miloslavina Y, Grouneva I, Lambrev PH, Lepetit B, Goss R, Wilhelm C, Holzwarth AR (2009) Ultrafast fluorescence study on the location and mechanism of non-photochemical quenching in diatoms. Biochim Biophys Acta 1787: 1189-1197

Nitschke U, Connan S, Stengel DB (2012) Chlorophyll a fluorescence responses of temperate Phaeophyceae under submersion and emersion regimes: a comparison of rapid and steadystate light curves. Photosynth Res 114: 29-42

Niyogi KK, Truong TB (2013) Evolution of flexible non-photochemical quenching mechanisms that regulate light harvesting in oxygenic photosynthesis. Curr Opin Plant Biol 16: 307-314

Ocampo-Alvarez H, García-Mendoza E, Govindjee (2013) Antagonistic effect between violaxanthin and de-epoxidated pigments in nonphotochemical quenching induction in the qE deficient brown alga Macrocystis pyrifera. Biochim Biophys Acta 1827: 427-437

Owens TG (1986) Light-harvesting function in the diatom Phaeodactylum tricornutum II. Distribution of excitation energy between the photosystems. Plant Physiol 80: 739-746

Passaquet C, Thomas JC, Caron L, Hauswith N, Puel F, Berkaloff C (1991) Light-harvesting complexes of brown algae. Biochemical characterization and immunological relationships. FEBS Lett 280: 21-26

Perkins RG, Mouget JL, Lefebvre S, Lavaud J (2006) Light response curve methodology and possible implications in the application of chlorophyll fluorescence to benthic diatoms. Mar Biol 149: 703-712

Perkins R, Lavaud J, Serôdio J, Mouget J-L, Cartaxana P, Rosa P, Barrillé L, Brotas V, Jesus B (2010) Vertical cell movement is the primary response of intertidal benthic biofilms to increasing light dose. Mar Ecol Prog Ser 416: 93-103

Perkins R, Kromkamp JC, Serôdio J, Lavaud J, Jesus B, Mouget J-L, Lefebvre S, Forster RM (2011) The application of variable chlorophyll fluorescence to microphytobenthic 
biofilms. In: Prasil O, Sugger D, Borowitzka MA (eds) Chlorophyll a Fluorescence in Aquatic Sciences: Methods and Applications, Developments in Applied Phycology, Volume 4, pp 237-276. Springer, Dordrecht

Petrou K, Doblin MA, Ralph PJ (2011) Heterogeneity in the photoprotective capacity of three Antarctic diatoms during short-term changes in salinity and temperature. Mar Biol 158: $1029-1041$

Philips N, Burrowes R, Rousseau F, de Reviers B, Saunders GW (2008) Resolving evolutionary relationships among the brown algae using chloroplast and nuclear genes. $\mathbf{J}$ Phycol 44: 394-405

Poulson ME, McNeil AJ, Donahue RA (2011) Photosynthetic response of Nereocystis luetkeana (Phaeophyta) to high light. Phycol Res 59: 156-165

Pyszniak AM, Gibbs SP (1992) Immunocytochemical localization of photosystem I and the fucoxanthin-chlorophyll a/c light-harvesting complex in the diatom Phaeodactylum tricornutum. Protoplasma 166: 208-217

Rodrigues MA, Santos CPD, Young AJ, Strbac D, Hall DO (2002) A smaller and impaired xanthophyll cycle makes the deep sea algae Laminaria abyssalis (Phaeophyceae) highly sensitive to daylight when compared with shallow water Laminaria digitata. J Phycol 38: 939-947

Ruban AV, Lavaud J, Rousseau B, Guglielmi G, Horton P, Etienne A-L (2004) The superexcess energy dissipation in diatom algae: comparative analysis with higher plants. Photosynth Res 82: 165-175

Ruban AV, Johnson MP, Duffy CDP (2012) The photoprotective molecular switch in the photosystem II antenna. Biochim Biophys Acta 1817: 167-181 
Saga G, Giorgetti A, Fufezan C, Giacometti GM, Bassi R, Morosinotto T (2010) Mutation analysis of violaxanthin de-epoxidase indentifies substrate-binding sites and residues involved in catalysis. J Biol Chem 285: 23763-23770

Salleh S, McMinn A (2011) The effects of temperature on the photosynthetic parameters and recovery of two temperate benthic microalgae, Amphora cf.coffeaeformis and Cocconeis cf. sublittoralis (Bacillariophyceae). J Phycol 47: 1413-1424

Schaller S, Latowski D, Jemiola-Rzeminska M, Wilhelm C, Strzalka K, Goss R (2010) The main thylakoid membrane lipid monogalactosyldiacylglycerol (MGDG) promotes the deepoxidation of violaxanthin associated with the light-harvesting complex of photosystem II (LHCII). Biochim Biophys Acta 1797: 414-424

Schaller S, Wilhelm C, Strzalka K, Goss R (2012) Investigating the interaction between the violaxanthin cycle enzyme zeaxanthin epoxidase and the thylakoid membrane. $\mathrm{J}$ Photochem Photobiol B: Biology 114: 119-125

Schofield O, Evens TJ, Mille DF (1998) Photosystem II quantum yields and xanthophyllcycle pigments of the macroalga Sargassum natans (Phaeophyceae): responses under natural sunlight. J Phycol 34: 104-112

Schumann A, Goss R, Jakob T, Wilhelm C (2007) Investigation of the quenching efficiency of diatoxanthin in cells of Phaeodactylum tricornutum (Bacillariophyceae) with different pool sizes of xanthophyll cycle pigments. Phycologia 46: 113-117

Serôdio J, Cruz S, Vieira S, Brotas V (2005) Non-photochemical quenching of chlorophyll fluorescence and operation of the xanthophyll cycle in estuarine microphytobenthos. $\mathrm{J}$ Exp Mar Biol Ecol 326: 157-169

Serôdio J, Vieira S, Cruz S (2008) Photosynthetic activity, photoprotection and photoinhibition in intertidal microphytobenthos as studied in situ using variable chlorophyll fluorescence. Contl Shelf Res 28: 1363-1375 
Serôdio J, Lavaud J (2011) A model for describing the light response of the nonphotochemical quenching of chlorophyll fluorescence. Photosynth Res 108: 61-76

Serôdio J, Ezéquiel J, Barnett A, Mouget J-L, Méléder V, Laviale M, Lavaud J (2012) Efficiency of photoprotection in microphytobenthos: role of vertical migration and the xanthophyll cycle against photoinhbition. Aquat Microb Ecol 67: 161-175

Szabo M, Lepetit B, Goss R, Wilhelm C, Mustardy L, Garab G (2008) Structurally flexible macro-organization of the pigment-protein complexes of the diatom Phaeodactylum tricornutum. Photosynth Res 95: 237-245

Strzepek RF, Harrison PJ (2004) Photosynthetic architecture differs in coastal and oceanic diatoms. Nature 431: 689-692

Su W, Jakob T, Wilhelm C (2012) The impact of nonphotochemical quanching of fluorescence on the photon balance in diatoms under dynamic light conditions. J Phycol 48: $336-346$

Tozzi S, Schofield O, Falkowski PG (2004) Historical climate change and ocean turbulence as selective agents for two key phytoplankton functional groups. Mar Ecol Prog Ser 274: $123-132$

Tuji A (2000) The effect of irradiance on the growth of different forms of freshwater diatoms: implications for succession in attached diatom communities. J Phycol 36: 659-661

Uhrmacher S, Hanelt D, Nultsch W (1995) Zeaxanthin content and the degree of photoinhibition are linearly correlated in the brown alga Dictyota dichotoma. Mar Biol 123: $159-165$

Underwood GJC, Kromkamp J (1999) Primary production by phytoplankton and microphytobenthos in estuaries. Adv Ecol Res 29: 93-153

Underwood GJC, Perkins RG, Consalvey MC, Hanlon ARM, Oxborough K, Baker NR, Paterson DM (2005) Patterns in microphytobenthic primary productivity: Species-specific 
variation in migratory rhythms and photosynthetic efficiency in mixed-species biofilms. Limnol Oceanogr 50: 755-767

Ursi S, Pedersén M, Plastino E, Snoeijs P (2003) Intraspecific variation of photosynthesis, respiration and photoprotective carotenoids in Gracilaria birdiae (Gracilariales: Rhodophyta). Marine Biol 142: 997-1007

van de Poll WH, Alderkamp A-C, Janknegt PJ, Roggeveld J, Buma AGJ (2006) Photoacclimation modulates excessive photosynthetically active and ultraviolet radiation effects in a temperate and an Antarctic marine diatom. Limnol Oceanogr 51: 1239-1248 van de Poll WH, Lagunas M, de Vries T, Visser RJW, Buma AGJ (2011) Non-photochemical quenching of chlorophyll fluorescence and xanthophyll cycle responses after excess PAR and UVR in Chaetoceros brevis, Phaeocystis antarctica and coastal Antarctic phytoplankton. Mar Ecol Prog Ser 426: 119-131

van Leeuwe MA, van Sikkelerus B, Gieskes WWC, Stefels J (2005) Taxon-specific differences in photoacclimation to fluctuating irradiance in an Antarctic diatom and a green flagellate. Mar Ecol Prog Ser 288: 9-19

van Leeuwe MA, Brotas V, Consalvey M, Forster RM, Gillespie D, Jesus B, Roggeveld J, Gieskes WWC (2009) Photacclimation in microphytobenthos and the role of the xanthophyll pigments. Eur J Phycol 43: 123-132

Veith T, Brauns J, Weisheit W, Mittag M, Büchel C (2009) Identification of a specific fucoxanthin-chlorophyll protein in the light-harvesting complex of photosystem I in the diatom Cyclotella meneghiniana. Biochim Biophys Acta 1787: 905-915

Wagner H, Jakob T, Wilhelm C (2006) Balancing the energy flow from captured light to biomass under fluctuating light conditions. New Phytol 169: 95-108 
Waring J, Underwoord GJC, Baker NR (2006) Impact of elevated UV-B radiation on photosynthetic electron transport, primary productivity and carbon allocation in estuarine epipelic diatoms. Plant Cell Envir 29: 521-534

Waring J, Baker NR, Underwoord GJC (2007) Responses of estuarine intertidal microphytobenthic algal assemblages to enhanced ultraviolet B radiation. Glob Change Biol 13: 1398-1413

Wiencke C, Bischof K (eds) (2012) Seaweed Biology: Novel Insights Into Ecophysiology, Ecology And Utilization, 510 pp. 219 Springer-Verlag, Berlin Heildeberg

Wilhelm C, Büchel C, Fisahn J, Goss R, Jakob T, LaRoche J, Lavaud J, Lohr M, Riebesell U, Stehfest K, Valentin K, Kroth PG (2006) The regulation of photosynthetic carbon and nutrient assimilation in diatoms is significantly different from green algae, a putative consequence of secondary endosymbiosis. Protist 157: 91-124

Wu H, Roy S, Alami M, Green BR, Campbell DA (2012) Photosystem II photoinactivation, repair, and protection in marine centric diatoms. Plant Physiol 160: 464-476

Yamamoto H, Nakayama T, Chichester C (1962) Studies on the light and dark interconversions of leaf xanthophylls. Arch Biochem Biophys 97: 168-173

Zhu S-H and Green BR (2010) Photoprotection in the diatom Thalassiosira pseudonana: Role of LI818-like proteins in response to high light stress. Biochim Biophys Acta 1797: 1449_ 1457 


\section{VAZ cycle}

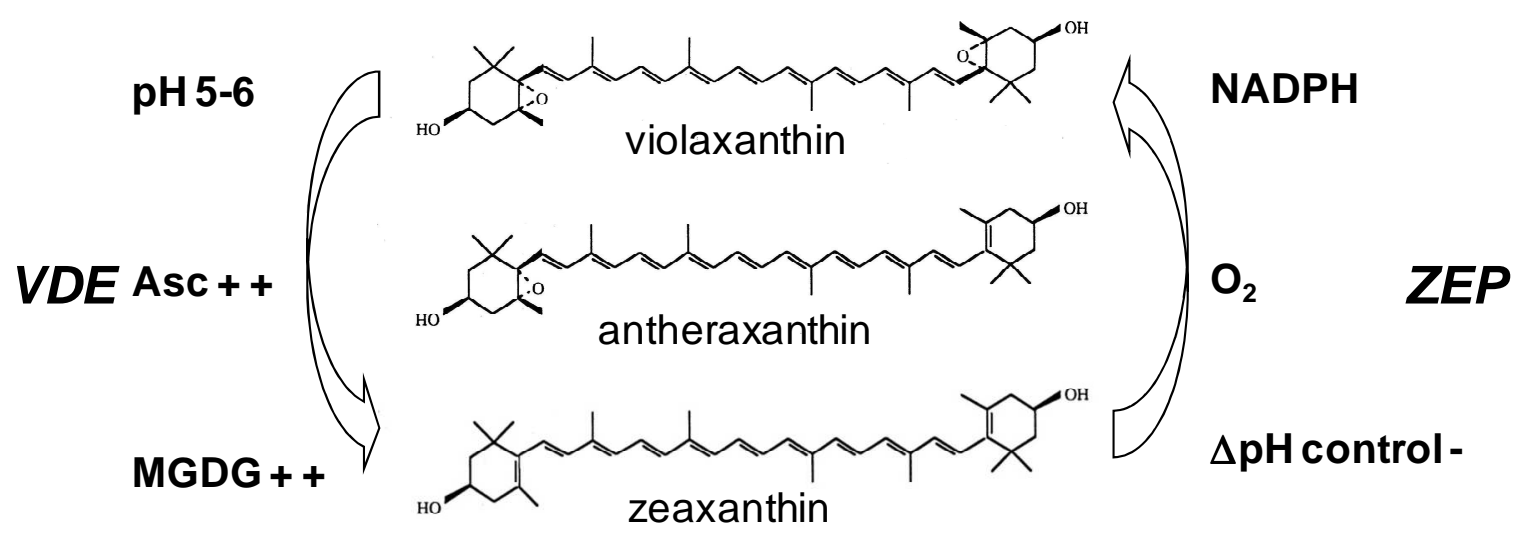

\section{Dd-Dt cycle}

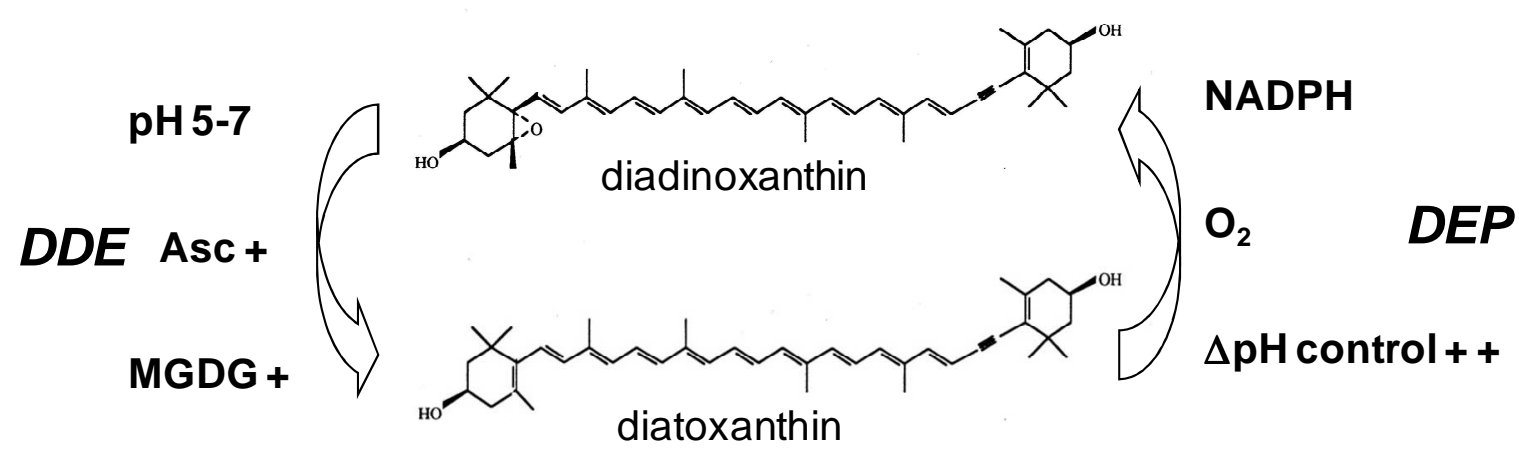

Fig. 1. Reaction sequence and enzymes of the VAZ and the Dd-Dt cycles. The VAZ cycle is the xanthophyll cycle (XC) of vascular plants as well as green and brown algae, the Dd-Dt cycle is the main $\mathrm{XC}$ of the algal classes Bacillariophyceae (diatoms), Xanthophyceae, Haptophyceae and Dinophyceae. The figure depicts the cofactor requirements of the enzymes VDE and DDE as well as ZEP and DEP. Symbols after the cofactors indicate that high (++) or only low (+) concentrations are needed for high enzyme activity. The figure shows that the transthylakoid proton gradient inhibits diatoxanthin (Dt) epoxidation (high $\Delta \mathrm{pH}$ control, ++) 
whereas zeaxanthin $(\mathrm{Z})$ epoxidation is unaffected by $\Delta \mathrm{pH}(-)$. The figure also depicts the $\mathrm{pH}$ range of the thylakoid lumen, where VDE and DDE are active (for more details, see the text). VDE/DDE: $\mathrm{V}$ and Dd de-epoxidase, respectively; ZEP/DEP: $\mathrm{Z}$ and $\mathrm{Dt}$ epoxidase, respectively; Asc: ascorbate, MGDG: monogalactosyl-diacylglycerol. 

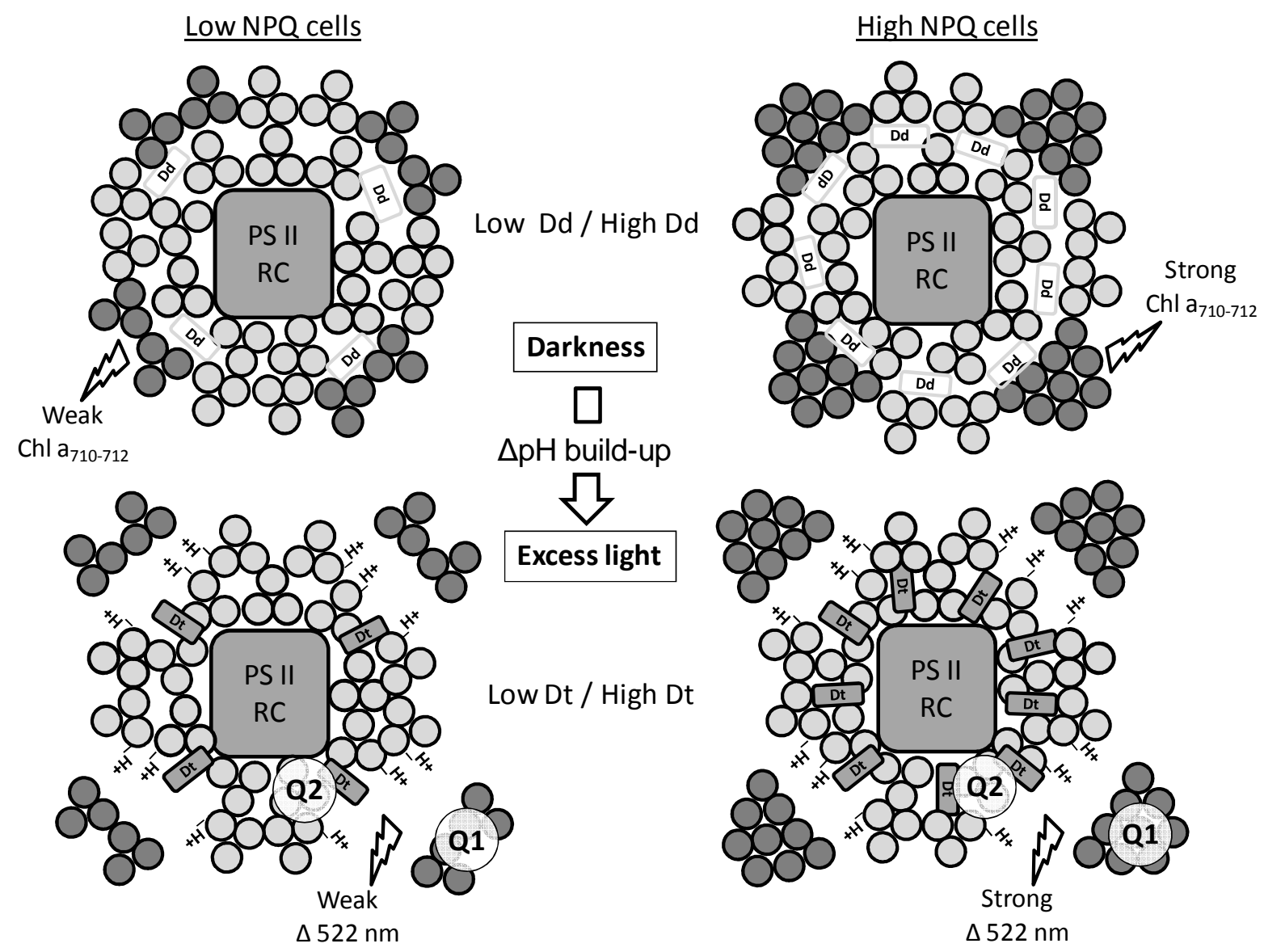

Fig. 2. A working hypothesis for xanthophyll-dependent energy dissipation (resulting in NPQ) in pennate diatoms depicting the organization of the PS II LHC antenna system in "low NPQ" and "high NPQ" cells dark-acclimated and exposed to excess light conditions, respectively (see also Büchel, Chap. 11). It should be noted that this model is based mainly on observations in P. tricornutum; differences observed in other species are discussed in the text (see Section III.A). Light and dark-grey circles are Fcp polypeptides forming trimers and higher FCP oligomeric complexes, respectively; the latter are loosely bound to the PS II LHC antenna system and can disconnect under excess light exposure. Chl $a_{710-712}$, chlorophyll $a$ fluorescence emission band between 710 and $712 \mathrm{~nm}$; Dd, diadinoxanthin; Dt, diatoxanthin; $\mathrm{H}^{+}$, protons; PS II RC, photosystem II reaction center, Q1/Q2, quenching sites 1 and 2; $\Delta \mathrm{pH}$, trans-thylakoid proton gradient; $\Delta 522 \mathrm{~nm}$, absorption change at $522 \mathrm{~nm} . \Delta 522 \mathrm{~nm}$ is a 
spectroscopic fingerprint that provides information on the engagement of Dt in energy dissipation (Ruban et al. 2004; Lavaud and Lepetit 2013), i.e. its effective involvement in NPQ. It is similar to the $\Delta 525-\Delta 535 \mathrm{~nm}$ in land plants (Jahns and Holzwarth 2012; Ruban et al. 2012). The model depicted here aims to illustrate the effective involvement of Dt as an allosteric regulator of a conformational change in the LHC antenna. The conformational change is believed to be an aggregation of part of the LHC antenna generated by the pronotation of FCP-binding sites (Goss et al. 2006b; Lavaud and Kroth 2006) (see also Büchel, Chap. 11). Chl $a_{710-712}$ is a spectroscopic fingerprint illustrating the ability to form oligomeric FCP complexes that disconnect from the PS II core under excess light conditions (Miloslavina et al. 2009; Lepetit et al. 2012) in order to amplify Dt-dependent energy dissipation and thus NPQ (Lavaud and Lepetit 2013). See the text for further details. 
Figure 1

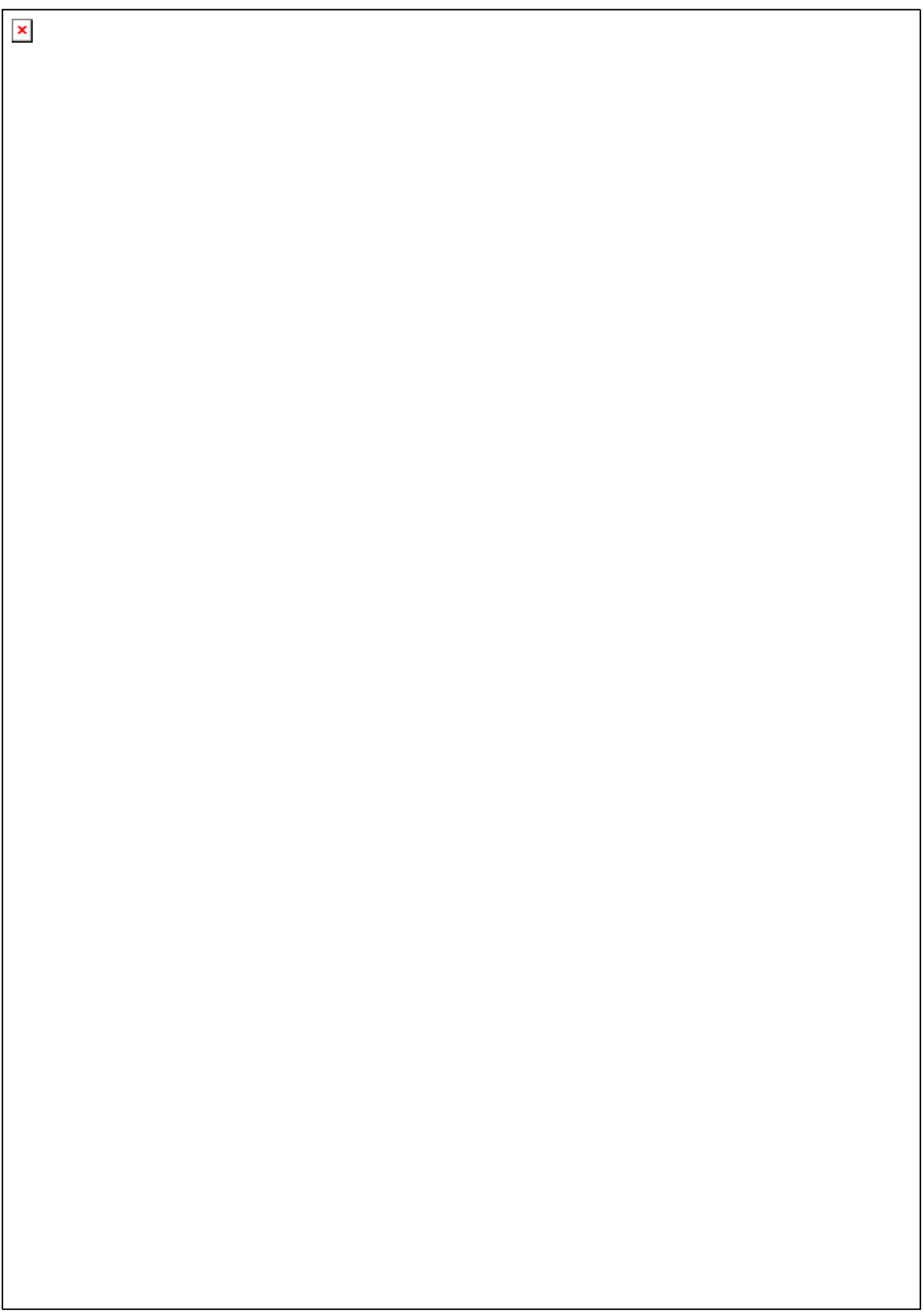


Figure 2
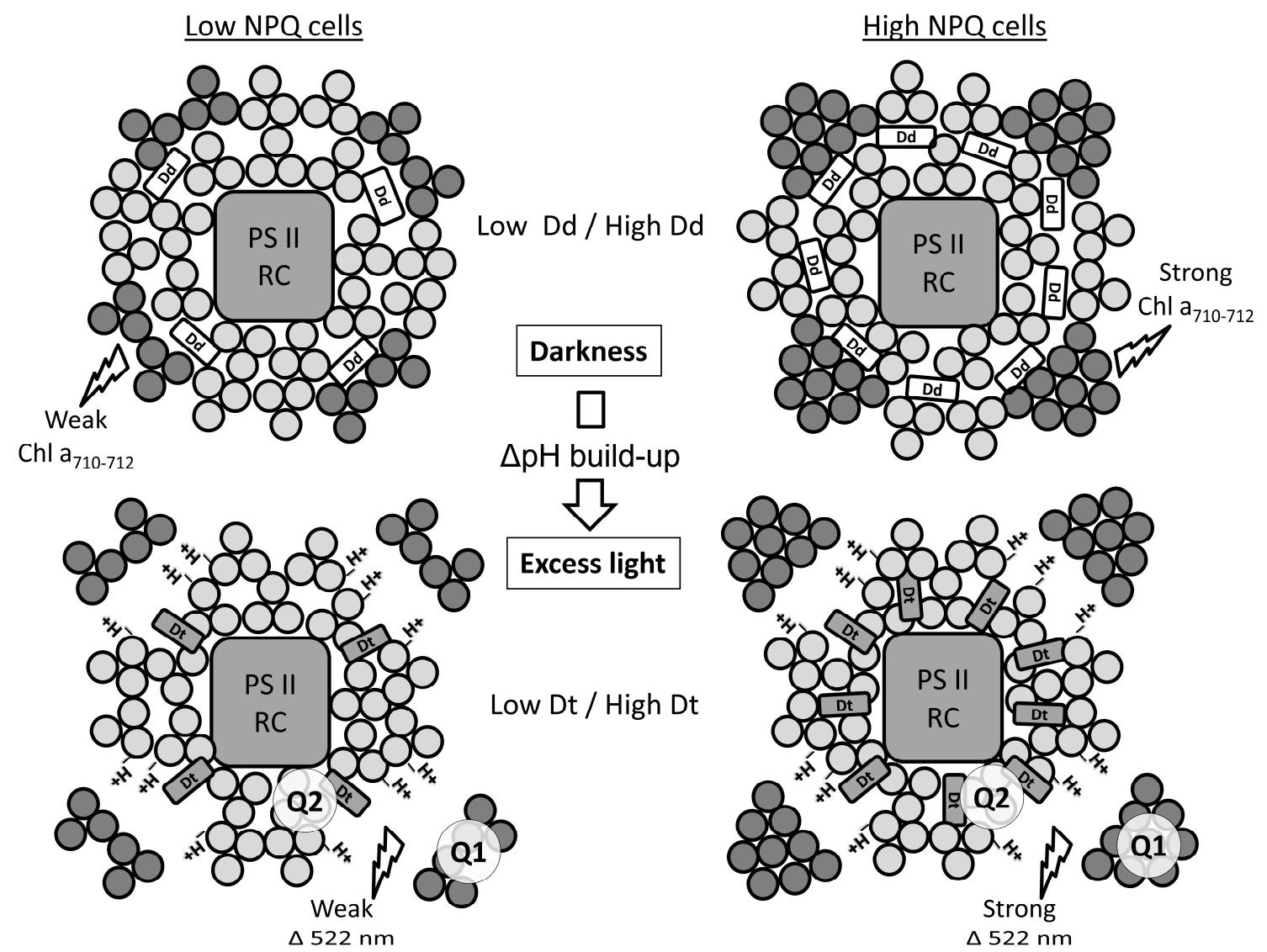